
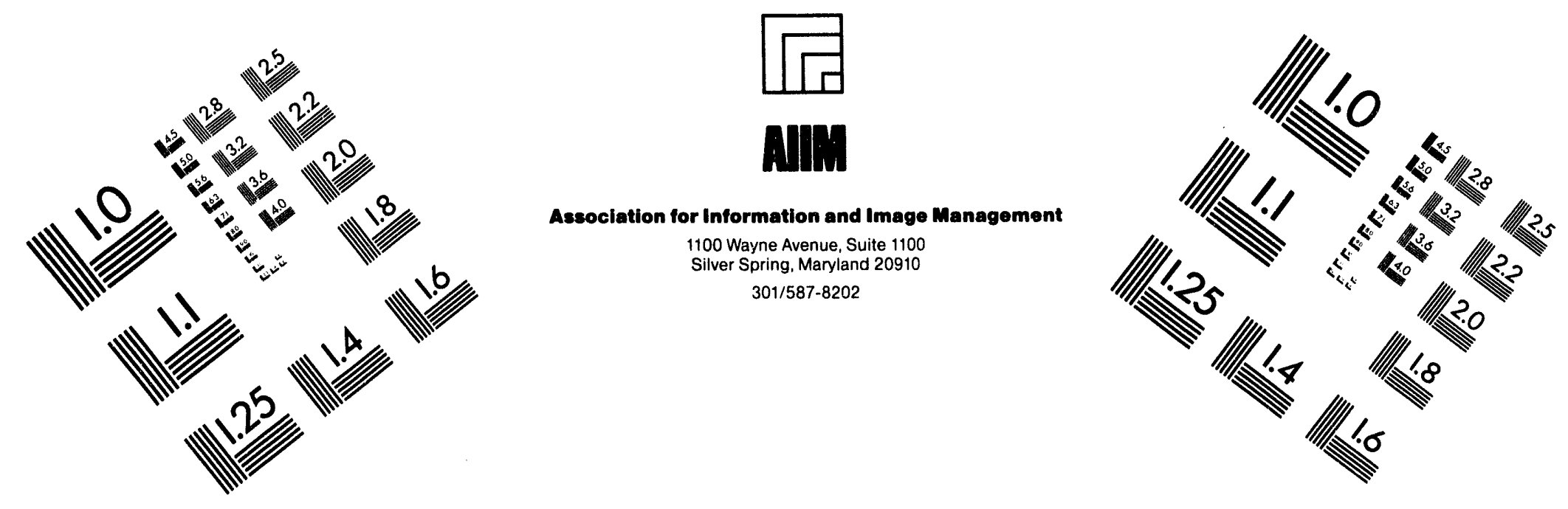

Centimeter

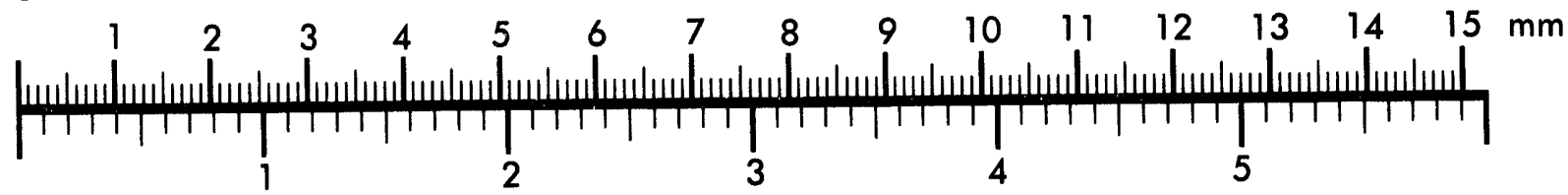

Inches
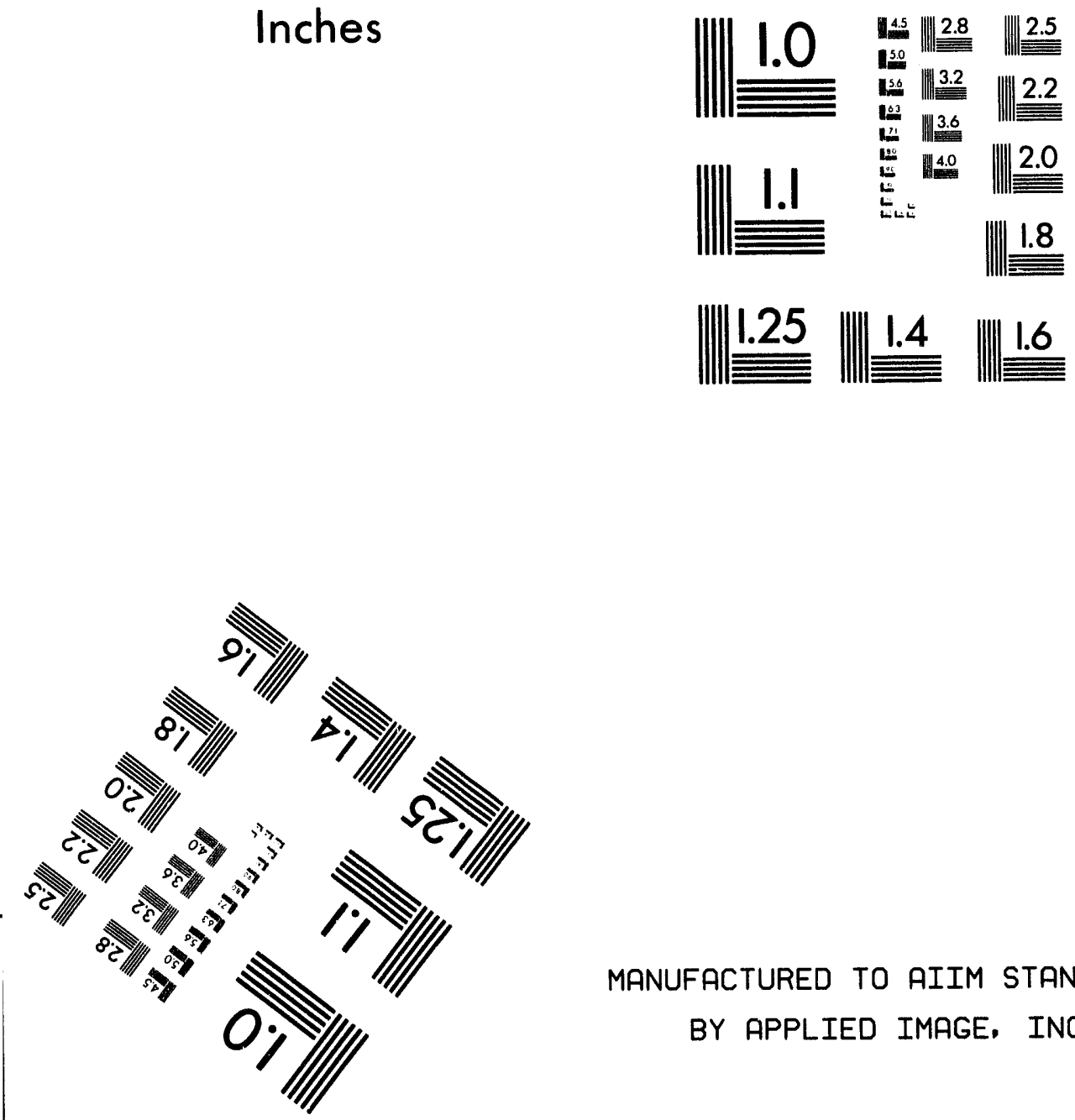

MANUFACTURED TO AIIM STANDARDS BY APPLIED IMAGE, INC.

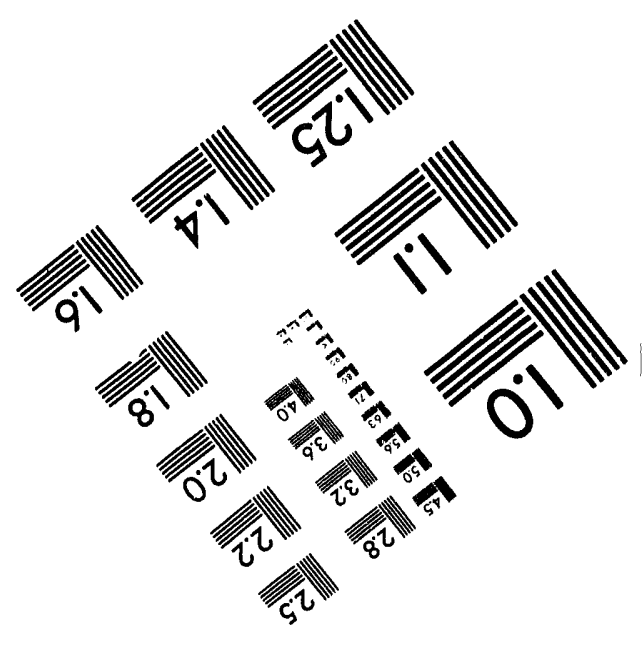



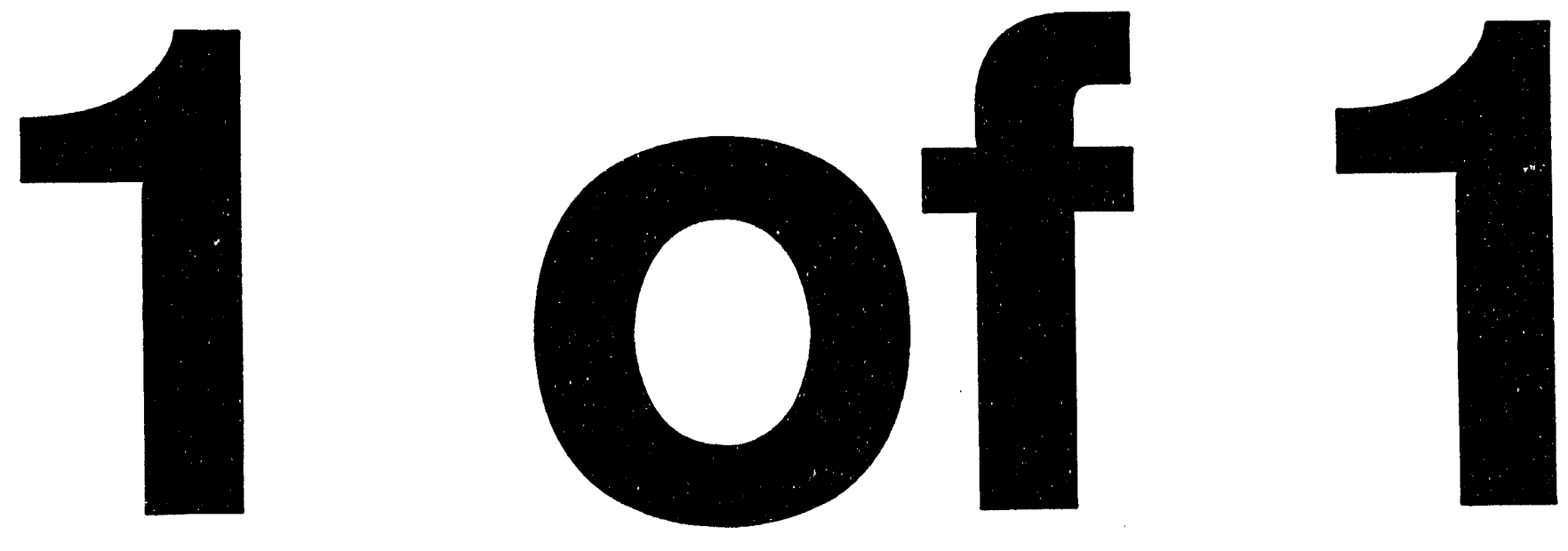


\section{DISCLAIMER PAGE}

This report has been reviewed by the U.S. Department of Energy and approved for publication. Approval does not signify that the contents necessarily reflect the view and policies of the DOE nor does mention of trade names or commercial products constitute endorsement of recommendation for use.

\section{RECEIVED \\ SEP 201994 \\ OSTI}

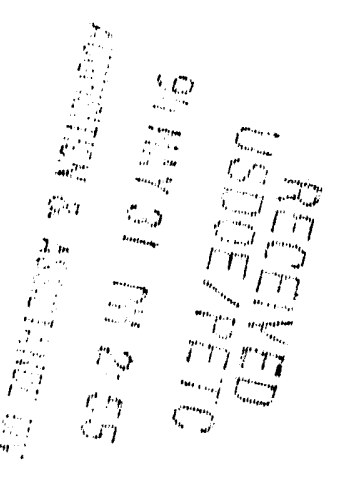




\title{
DISCLAIMER
}

This report was prepared as an account of work sponsored by an agency of the United States Government. Neither the United States Government nor any agency thereof, nor any of their employees, makes any warranty, express or implied, or assumes any legal liability or responsibility for the accuracy, completeness, or usefulness of any information, apparatus, product, or process disclosed, or represents that its use would not infringe privately owned rights. Reference herein to any specific commercial product, process, or service by trade name, trademark, manufacturer, or otherwise does not necessarily constitute or imply its endorsement, recommendation, or favoring by the United States Government $r r$ any agency thereof. The views and opinions of authors expressed herein do not necessarily state or reflect those of the United States Government or any agency thereof.

\section{DEVELOPMENT OF A MEMBRANE-BASED PROCESS FOR THE TREATMENT OF OILY WASTE WATERS}

\author{
Final Report \\ Contract No. DE-AC22-92MT92005 \\ May 25, 1994 \\ Contract Date: March 4, 1992 \\ Anticipated Completion Date: April 1, 1994 \\ Government Award for FY1994: \$0 \\ Program Manager: Scott B. McCray \\ Principal Investigator: Scott B. McCray \\ Technical Project Officer (COR): Gene Pauling \\ Reporting Period: March 4, 1992, to March 5, 1994 \\ from \\ Bend Research, Inc. \\ 64550 Research Road \\ Bend, Oregon 97701-8599
}

NOTE: US/DOE Patent Clearance is not required prior to the publication of this document. 


\section{TABLE OF CONTENTS}

\section{Page}

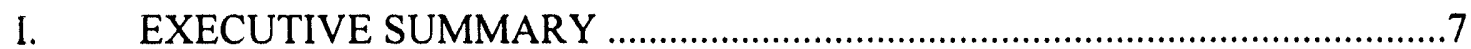

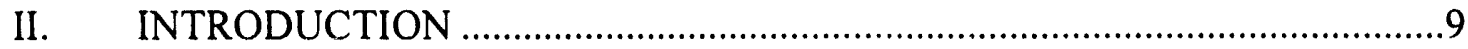

III. DEVELOPMENT OF SOLVENT-RESISTANT HOLLOW FIBERS ................11

IV. SELECTION COATING AND SCALE-UP OF MODULES ...............................18

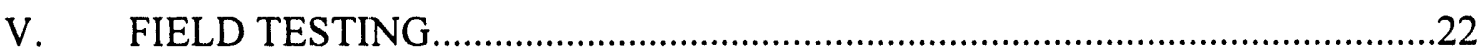

VI. CONCLUSIONS AND RECOMMENDATIONS …........................................

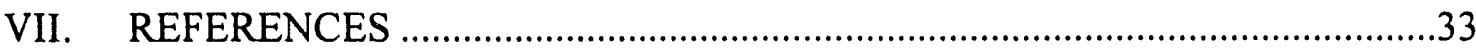

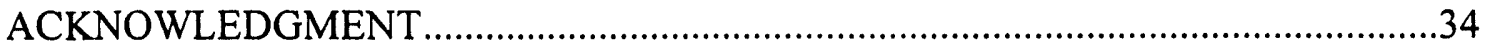




\section{LIST OF TABLES}

Table I. Summary of Fiber-Spinning Targets and Performance of Fibers Developed

Table II. Results of Solvent-Resistance Tests of Flat-Sheet Polymers

Table III. Properties of Initial Fibers Made From Polymer A

Table IV. Properties of Improved Fibers Made From Polymer A

Table V. Properties of Fibers Made From Polymer B

Table VI. Effect of Solvent Exposure on the Burst Pressure of Hollow-Fiber Supports

Table VII. Effect of Temperature on the Burst Pressure of Fibers

Table VIII. Performance of Modules Containing Fibers Coated With TTM Loose-RO Coatings

Table IX. Results of Evaluations of $0.1-\mathrm{m}^{2}$ Modules

Table X. Performance of Large-Scale (1- $\left.\mathrm{m}^{2}\right)$ TTM-40 Modules

Table XI. Summary of Preliminary Field Tests 


\section{LIST OF FIGURES}

Figure 1. SEM of the Cross Section of a Solvent-Resistant Hollow Fiber Made Using Polymer A

Figure 2. SEM of the Cross Section of a Solvent-Resistant Hollow Fiber Made Using Polymer B

Figure 3. Flux as a Function of Time for Module 1091-77B $\left(0.1 \mathrm{~m}^{2}\right)$ Operating on Synthetic Oily Water

Figure 4. Feed and Permeate Concentrations of Oil and Grease for Module 1091-77B $\left(0.1 \mathrm{~m}^{2}\right)$ Operating on Synthetic Oily Water

Figure 5. Test Loop Used During Preliminary Field Tests

Figure 6. Performance of TTM-20 Hollow Fiber Module During Preliminary Field Tests at Friendswood, Texas

Figure 7. Demonstration Unit

Figure 8. Relative Water Flux Versus Transmembrane Pressure for TTM-20 and TTM-60 Hollow-Fiber Modules

Figure 9. Effect of Osmotic Pressure on Membrane Performance

Figure 10. Water Permeability Versus Transmembrane Pressure for TTM-20 and TTM-60 Hollow-Fiber Modules

Figure 11. Water Permeability Versus Time for TTM-20 and TTM-60 Hollow-Fiber Modules

Figure 12. Water Flux as a Function of Time for the Demonstration Test

Figure 13. Feed-Flow Rate as a Function of Time During the Demonstration Test

Figure 14. Water Recovery as a Function of Time During the Demonstration Test 


\begin{abstract}
The goal of this program was to develop an economical oily-water treatment system based on reverse-osmosis (RO) membrane technology. The RO system would be used to 1) reduce oil-production costs by reducing the volume of waste water for which disposal is required; 2) form the basis of a generic waste-water treatment system that can easily be integrated into oil-field operations, especially at production facilities that are small or in remote locations; and 3) produce water clean enough to meet current and anticipated environmental regulations.
\end{abstract}

The specific focus of this program was to develop a hollow-fiber membrane module capable of treating oily waste waters. Typically, the organics in oily waste water swell or dissolve the materials used in conventional polymeric membranes and modules. Our goal was to develop hollow-fiber membranes and modules that were more solvent-resistant than conventional membrane modules.

We successfully achieved this goal. During the course of this program, we developed thin-film-composite (TFC) membranes, which consisted of a solvent-resistant selective coating placed on a solvent-resistant hollow-fiber support. These TFC membranes were used in lowcost, hollow-fiber modules, which were made using solvent-resistant comp onents. The modules were tube-side-feed modules, in which the oily waste water travels down ine inside (lumen) of the hollow fiber. The selective coating allows water to pass freely through the wall of the fiber, but restricts the transport of oil and grease and some of the dissolved organics and salts in the feed. Using these modules, more than $90 \%$ of the oily waste water can be recovered as clean permeate (suitable for discharge), while the remaining $10 \%$ is removed as oily-water concentrate (which can be recycled for recovery of the oil or disposed of in an environmentally acceptable manner).

During this program, we successfully fabricated membranes with high solvent resistance. The properties of these membranes showed little or no change when the membranes were soaked in pure solvents such as toluene or gasoline. The solvent-resistant modules developed in this program were successfully field-tested on actual oily-water streams. During demonstration tests, the modules were operated for more than 2000 hours. The tests showed the permeate produced by the modules was sufficiently clean to meet discharge regulations. With improvements in the pretreatment system, the technology developed in this program should be capable of maintaining high water fluxes and treating oily waters effectively. 


\section{EXECUTIVE SUMMARY}

This is a final report from Bend Research, Inc., (BRI) to the U.S. Department of Energy (DOE) for work performed under Contract No. DE-AC22-92MT92005, titled "Development of a Membrane-Based Process for the Treatment of Oily Waste Waters." This report covers the period from March 4, 1992, to March 5, 1994.

The overall goal of this program was to develop an economical oily-water treatment system based on reverse osmosis (RO). The RO system would be used to 1) reduce oilproduction costs by reducing the volume of waste water that must be disposed of; 2) form the basis of a generic waste-water treatment system that can easily be integrated into oil-field operations, especially at production facilities that are small or in remote locations; and 3) produce water clean enough to meet existing and anticipated environmental regulations.

The specific focus of this program was the development of a hollow-fiber membrane module capable of treating oily waste waters. Typically, the organics in oily waste waters swell or dissolve the materials used in conventional polymeric membranes and modules. Our goal was to develop hollow-fiber membranes and modules that were more solvent-resistant than conventional membrane modules. We successfully achieved this goal. The membranes developed in this program were thin-film-composite (TFC) membranes, which consist of a selective coating placed on a hollow-fiber support. These TFC membranes are piaced into a lowcost tube-side-feed module. In this configuration, feed solution (i.e., oily wastr: water) travels down the inside (or lumen) of the hollow fiber. The selective coating allows water to pass freely through the wall of the fiber but restricts the transport of oil and grease and some of the dissolved organics and salts in the feed. The clean permeate exits the shell of the module, whereas the concentrated retentate stream exits the fikers from the other end of the module. More than $90 \%$ of the oily waste water can be recovered as clean permeate, while the remaining $10 \%$ is oily water concentrate. The recovered permeate is suitable for discharge, and the concentrate can be recycled for recovery of tile oil and/or disposed of in an environmentally friendly manner.

The design of the tube-side-feed hollow-fiber module is an important element in the design of the oily-water treatment system. Because the feed flows straight down the fiber lumen, the stream lines are laminar and well-defined, and no channeling occurs. This makes the tubeside-feed hollow-fiber module resistant to fouling, allowing for high water fluxes.

During this program, we started by identifying membrane polymers that have the requisite solvent resistance. We then developed procedures to make hollow-fiber supports from these polymers. Tests showed that these supports have excellent solvent resistance, showing little or no change in properties when soaked in pure solvents such as toluene or gasoline. 
Materials were then identified that can be used to make solvent-resistant modules. Specifically, solvent-resistant potting compounds were identified that have the same solvent resistance as the solvent-resistant hollow-fiber supports. When used to pot (or immobilize) the hollow fibers in stainless steel module housing, the resulting module had sufficient solvent resistance for treatment of oily waste waters.

Once the solvent-resistant module had been developed, we focused on selecting a solvent-resistant elective coating. We found that the TTM series of coatings previously developed at Bend Research had high rejections for oil and grease and produced high water fluxes. ${ }^{*}$

We applied TTM coatings to solvent-resistant hollow-fiber supports in a solvent-resistant module and performed several field tests. First, small-scale modules were tested using a small, portable test unit. These preliminary field tests showed that the TTM hollow-fiber modules produced a clean permeate and maintained high water fluxes.

A demonstration test of this technology was then performed. Parametric tests were used to determine the appropriate operating conditions for the modules, and long-term tests were performed. During the demonstration tests, modules were operated for more than 2000 hours. The demonstration tests showed that the permeate produced by the modules was sufficiently clean for discharge. Unfortunately, difficulties with the pretreatment system during the demonstration test led to variations in water flux.

We are confident, however, that with an improved pretreatment system, the technology developed for this program will maintain high water fluxes and can be used effectively to treat oily waste waters, producing a clean permeate stream suitable for discharge.

As an outgrowth of this program, we are continuing development of these solventresistant membrane modules for a variety of applications, many of which are energy-related. The initial commercial application of these modules will likely not be for the treatment of oily waste water, since deployment of this technology in the oil and gas industry will likely be difficult without market acceptance in other industry segments. Instead, we intend to focus our initial commercialization efforts on applications in niche markets where the barriers to market entry are lower. After building industrial acceptance of our solvent-resistant membrane technology for other uses, we hope to introduce products based on the oily-water treatment technology developed in this program.

* This patented series of coatings was developed previously in a DOE program (McCray et al., 1988; McCray, 1989). 


\section{INTRODUCTION}

\section{II.A. OBJECTIVES}

The production of oil generates large quantities of waste water. In some cases, more than $90 \%$ of the fluid pumped from oil wells is waste water. Typically, these waste waters have four major contaminants: 1) oil and grease; 2) suspended solids; 3 ) dissolved organics (e.g., lowmolecular-weight carboxylic acids); and 4) dissolved solids (e.g., salts). In the past, it was common to dump this waste water into surface streams, ponds, or the ocean-a practice that can result in environmental damage. Today, the discharge of waste waters into surface waters is restricted, and regulatory agencies require that discharged waste must be virtually free of oil and grease.

The overall goal of this program was to develop an economical oily-water treatment system based on reverse osmosis (RO). In this process, a feed solution containing oil and grease and other contaminants is pressurized and fed to an RO membrane. The membrane is designed to restrict the passage of contaminants, producing a "permeate" stream that is sufficiently clean for discharge. The contaminants are concentrated by this process and exit as the "retentate." The RO process would be used to 1) reduce oil-production costs by reducing the volume of waste water that must be disposed of; 2) form the basis of a generic waste-water treatment system that can easily be integrated into oil-field operations, especially at production facilities that are smaller in remote locations; and 3) produce water clean enough to meet existing and anticipated environmental regulations.

\section{II.B. SCOPE OF STUDY}

In previous work for the U.S. Department of Energy, we developed and demonstrated the feasibility of a two-stage membrane-based system for treating oily waste waters. Although this previous work was a success, the results showed that an additional innovation was required before this technology could become commercially viable: the development of hollow-fiber membranes that are resistant to the organic chemicals present in the oily waste waters. This was necessary to develop membrane modules with longer lifetimes, thus reducing costs. The specific focus of this program was the development of these solvent-resistant hollow-fiber membranes and their incorporation into a system for treating oily waste waters.

\section{II.C. METHODS AND APPROACH}

To achieve the goals of this program, we used the following approach. First, we developed solvent-resistant hollow-fiber supports. These fibers are made from materials that do 
not dissolve or swell excessively when exposed to the chemicals and solvents found in oily waste waters.

Second, we placed a "loose RO" coating on the inside surface of these fibers, forming a TFC nanofiltration membrane. This coating provides the selectivity of the TFC membrane.

Third, we scaled up this technology to a size suitable for field testing. Specifically, we made several modules containing $1 \mathrm{~m}^{2}$ of membrane area.

Fourth, we performed a field test of this technology. This field test, conducted near Houston, Texas, was performed in conjunction with our commercialization/manufacturing partner, AquaAir Environmental, Inc. (AAE) of Bend, Oregon.

\section{II.D. ORGANIZATION OF THE REPORT}

This report is organized as follows. The results of our work developing the solventresistant hollow fibers is presented in Section III. A discussion of our selection of the coating and scale-up to larger modules is presented in Section IV. A description of the field tests performed is presented in Section V. Finally, our conclusions and recommendations for further work are included in Section VI. 


\section{DEVELOPMENT OE SOLVENT-RESISTANT HOLLOW FIBERS}

The purpose of this work was to develop and evaluate hollow fibers made from solventresistant polymers. Table I gives the target properties for these hollow fibers, as well as typical properties of the fibers developed in this program. These targets were established by Bend Research in conjunction with our commercialization partner, who provided matching funds for this program.

Table I. Summary of Fiber-Spinning Targets and Performance of Fibers Developed

\begin{tabular}{lcccc}
\multicolumn{1}{c}{ Item } & Target & $\begin{array}{c}\text { Polymer A } \\
\text { (Initial) }\end{array}$ & $\begin{array}{c}\text { Polymer A } \\
\text { (Improved) }\end{array}$ & $\begin{array}{c}\text { Polymer B } \\
\text { Fibers }\end{array}$ \\
\hline Internal diameter $(\mu \mathrm{m})$ & 300 & 410 & 370 & 400 \\
Wall thickness $(\mu \mathrm{m})$ & 100 & 85 & 100 & 130 \\
Burst pressure $(\mathrm{atm})$ & & & & \\
at $25^{\circ} \mathrm{C}$ & - & 22 & 39 & 38 \\
at $60^{\circ} \mathrm{C}$ & 28 & 9 & 38 & 33 \\
Gas permeability $\left(\mathrm{Nm}^{3} / \mathrm{m}^{2}\right.$-hr-atm) & 90 & 190 & 120 & 4
\end{tabular}

Work in this task was divided into three areas: 1) selection of the polymer,

2) identification of fiber-spinning conditions, and 3) evaluation of the fibers. Details of our work follow.

\section{III.A. SELECTION OF POLYMER}

Key to the success of our program was finding a polymer with the solvent resistance needed for this application. A literature search and discussions with various consultants and contacts led to a list of candidate polymers, three of which are commercially available; therefore, they became the focus of our work. ${ }^{*}$ In this report, these polymers are designated Polymer A, B, and $\mathrm{C}$.

To screen the three commercially available polymers, flat-sheet, nonporous films were made and then soaked in various solvents for extended periods of time. The results of these tests are given in Table II. Also included in this table are results for several conventional polymers that we have previously used to spin hollow fibers. As these results show, all three candidate polymers performed well, showing very little uptake of the solvents, except methylene chloride. The weight for the three polymers changed little when they were exposed to gasoline, toluene, or

\footnotetext{
${ }^{*}$ Patents are currently being prepared on this technology. Therefore, information on the polymers is not provided.
} 
Table II. Results of Solvent-Resistance Tests of Flat-Sheet Polymers

Conditions: Soak tests of nonporous polymer films, $22^{\circ} \mathrm{C}$

Weight Change (\%)

\begin{tabular}{|c|c|c|c|c|c|c|c|}
\hline \multirow[b]{2}{*}{ Solvent } & \multirow{2}{*}{$\begin{array}{c}\text { (soak } \\
\text { time) }\end{array}$} & \multicolumn{3}{|c|}{ Candidate Folymers } & \multicolumn{3}{|c|}{ Conventional Polymers } \\
\hline & & Polymer A & Polymer B & Polymer C & Ultem $^{*}$ & PES $^{*}$ & Kynar* \\
\hline \multirow[t]{2}{*}{ Gasoline } & $(72 \mathrm{hr})$ & -1 & 1 & 1 & 1 & 3 & 2 \\
\hline & (240 hr) & 0 & 1 & 1 & 1 & 2 & 2 \\
\hline \multirow[t]{2}{*}{ Toluene } & $(72 \mathrm{hr})$ & 0 & 0 & -2 & -1 & 1 & 3 \\
\hline & $(240 \mathrm{hr})$ & 1 & 1 & 0 & -1 & 0 & 4 \\
\hline \multirow[t]{2}{*}{ Xylene } & (72 hr) & -1 & 0 & -4 & -1 & 0 & 1 \\
\hline & $(240 \mathrm{hr})$ & -1 & 0 & -3 & -3 & 0 & 4 \\
\hline \multirow[t]{2}{*}{ Methanol } & (72 hr) & 3 & 3 & 5 & 5 & 2 & 3 \\
\hline & $(240 \mathrm{hr})$ & 4 & 7 & 4 & 8 & 4 & 0 \\
\hline \multirow{2}{*}{$\begin{array}{c}\text { Methylene } \\
\text { chloride }\end{array}$} & $(72 \mathrm{hr})$ & 24 & 3 & 29 & Dis $^{\star *}$ & Dis & 5 \\
\hline & $(240 \mathrm{hr})$ & 24 & 10 & 23 & & & 2 \\
\hline \multirow[t]{2}{*}{ Acetone } & $(72 \mathrm{hr})$ & 1 & 0 & 1 & 4 & Dis & 8 \\
\hline & $(240 \mathrm{hr})$ & 3 & 3 & 4 & & & 6 \\
\hline \multirow[t]{2}{*}{ DMAC $^{+}$} & (72 hr) & 0 & 0 & -1 & Dis & Dis & 44 \\
\hline & $(240 \mathrm{hr})$ & 2 & 1 & -1 & & & Dis \\
\hline \multirow[t]{2}{*}{$\mathrm{NMP}^{++}$} & (72 hr) & -1 & 2 & -1 & Dis & Dis & 58 \\
\hline & $(240 \mathrm{hr})$ & 1 & 7 & 2 & & & Dis \\
\hline Heptanol & $(72 \mathrm{hr})$ & 1 & 10 & -3 & 1 & 1 & 1 \\
\hline
\end{tabular}

xylene. This suggests that these polymers are suitable for use in making solvent-resistant hollow fibers.

\section{III.B. IDENTIFICATION OF FIBER-SPINNING CONDITIONS}

Several batches of hollow fibers were spun to identify the spinning conditions that produce fibers with the requisite properties.

Figure 1 shows a scanning electron microphotograph (SEM) of a cross section of an improved Polymer A fiber. Tables III and IV give the properties of the initial and improved Polymer A fibers, respectively. As these data show, the improved Polymer A fibers meet the targets set for this program (Table I). 


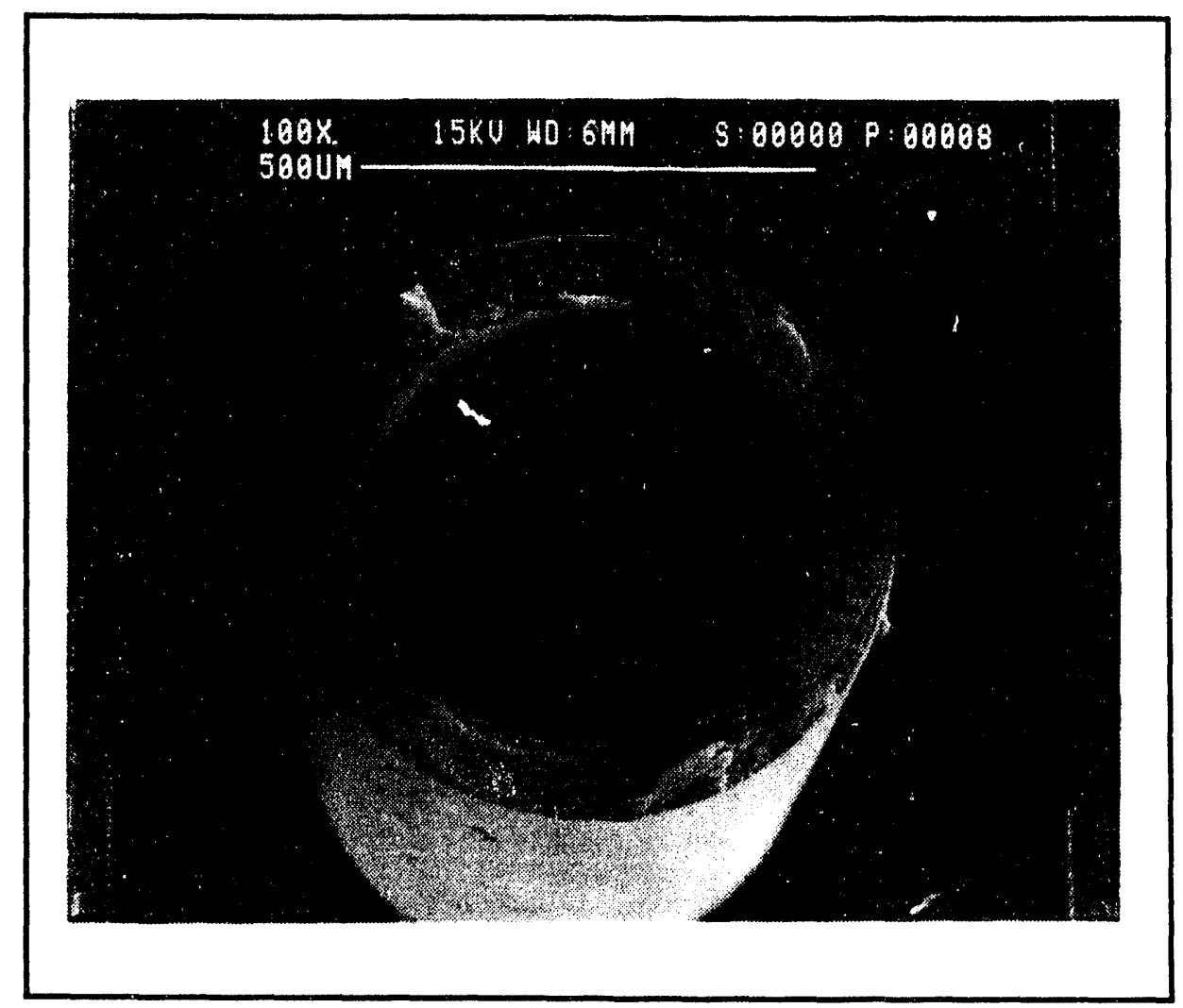

Figure 1. SEM of the Cross Section of an Improved Polymer A Fiber

Table III. Properties of Initial Polymer A Fibers

\begin{tabular}{|c|c|c|c|c|c|}
\hline Batch & $\begin{array}{l}\text { Internal } \\
\text { Diameter } \\
(\mu \mathrm{m})\end{array}$ & $\begin{array}{c}\text { Wall } \\
\text { Thickness } \\
(\mu \mathrm{m})\end{array}$ & $\begin{array}{c}\text { Burst } \\
\text { Pressure } \\
\text { (atm) }\end{array}$ & $\begin{array}{c}\text { Wet } \\
\text { Pressure } \\
\text { (atm) }\end{array}$ & $\begin{array}{c}\text { Air } \\
\text { Permeability } \\
\left(\mathrm{Nm}^{3} / \mathrm{m}^{2} \text {-hr-atm) }\right.\end{array}$ \\
\hline $\mathrm{C} 2-03-12$ & 400 & 90 & 22 & None & None \\
\hline C2-03-19A & 450 & 80 & 27 & 5.4 & 2 \\
\hline C2-03-19B & 425 & 90 & 27 & 3.7 & 85 \\
\hline$C 2-03-24 A$ & 415 & 90 & 24 & 5.1 & 7 \\
\hline C2-03-26 & 470 & 30 & 15 & 1.7 & 185 \\
\hline C2-03-27 & 460 & 100 & 29 & 3.0 & 105 \\
\hline C2-04-21B & 495 & 80 & 26 & 2.7 & 55 \\
\hline C2-04-21D & 560 & 75 & 16 & 9.8 & 7 \\
\hline C2-04-28A & 385 & 95 & 17 & 2.7 & 120 \\
\hline C2-04-28C & 375 & 115 & 27 & 3.4 & 85 \\
\hline$C 2-04-30 A$ & 400 & 80 & 13 & 3.4 & 160 \\
\hline C2-04-30D & 380 & 90 & 27 & 3.0 & 150 \\
\hline C2-05-19A & 470 & 80 & 18 & 3.4 & 250 \\
\hline C2-5-27A & 330 & 85 & 21 & 5.0 & 95 \\
\hline C2-5-27B & 330 & 85 & 23 & 2.7 & 240 \\
\hline C2-6-02A & 385 & 85 & 24 & 2.7 & 315 \\
\hline
\end{tabular}


Table IV. Properties of Improved Polymer A Fibers

\begin{tabular}{lccccc}
\multicolumn{1}{c}{ Batch } & $\begin{array}{c}\text { Internal } \\
\text { Diamoter } \\
(\boldsymbol{\mu \mathbf { m } )}\end{array}$ & $\begin{array}{c}\text { Wall } \\
\text { Thickness } \\
(\boldsymbol{\mu \mathbf { m } )}\end{array}$ & $\begin{array}{c}\text { Burst } \\
\text { Pressure } \\
(\mathbf{a t m})\end{array}$ & $\begin{array}{c}\text { Wet } \\
\text { Pressure } \\
(\mathbf{a t m})\end{array}$ & $\begin{array}{c}\text { Air } \\
\text { Permeability } \\
\left(\mathbf{N m} \mathbf{3}^{\mathbf{3}} \mathbf{m} \text {-hr-atm }\right)\end{array}$ \\
\hline C2-6-09A & 370 & 95 & 11 & 2.0 & 250 \\
C2-6-09AS & 370 & 95 & 25 & 2.7 & 325 \\
C2-6-17ABC & 285 & 95 & 45 & 2.4 & 285 \\
C2-6-17DE & 325 & 110 & 47 & 3.7 & 235 \\
C2-6-25A & 330 & 105 & 54 & 3.0 & 255 \\
C2-6-25C & 385 & 90 & 36 & 3.0 & 230 \\
C2-6-30C & 380 & 90 & 30 & 2.0 & 130 \\
C2-7-02A & 380 & 90 & 45 & 3.4 & 110 \\
C2-7-02B & 370 & 80 & 44 & 3.0 & 110 \\
C2-7-14A-J & 380 & 110 & 44 & 3.4 & 80 \\
C2-7-16A-L & 365 & 115 & 44 & 3.4 & 120
\end{tabular}

Our work with Polymer B was not as extensive as our work with Polymer A. However, the data in Table $\mathrm{V}$ show, we made excellent progress with Polymer B. Figure 2 shows an SEM of a Polymer B fiber.

Table V. Properties of Polymer B Fibers

\begin{tabular}{|c|c|c|c|c|c|}
\hline Batch & $\begin{array}{l}\text { Internal } \\
\text { Diameter } \\
(\mu \mathrm{m})\end{array}$ & $\begin{array}{l}\text { Wall } \\
\text { Thickness } \\
(\mu \mathrm{m})\end{array}$ & $\begin{array}{l}\text { Burst } \\
\text { Pressure } \\
\text { (atm) }\end{array}$ & $\begin{array}{l}\text { Wet } \\
\text { Pressure } \\
\text { (atm) }\end{array}$ & $\begin{array}{c}\text { Air } \\
\text { Permeability } \\
\left(\mathrm{Nm}^{3} / \mathrm{m}^{2} \text {-hr-atm }\right)\end{array}$ \\
\hline$\overline{C 02-03-04 A}$ & 400 & 105 & 16 & 15 & 2 \\
\hline C02-03-04B & 480 & 80 & 12 & 9 & 3 \\
\hline $\mathrm{CO2}-03-11$ & 390 & 110 & 22 & $>22$ & None \\
\hline C02-04-09A & 500 & 170 & 55 & 31 & 0.1 \\
\hline CO2-04-09B & 500 & 170 & 28 & 12 & 6 \\
\hline CO2-04-09C & 320 & 200 & 80 & 18 & 7 \\
\hline CO2-04-22A & 510 & 100 & 24 & 14 & 4 \\
\hline$C O 2-04-22 D$ & 495 & 60 & 15 & 12 & 3 \\
\hline L2-7-22A & 350 & 195 & -- & -- & -- \\
\hline L2-7-22B & 245 & 170 & 45 & 15 & 7 \\
\hline$L 2-7-28 A$ & 260 & 155 & 46 & 12 & 9 \\
\hline
\end{tabular}




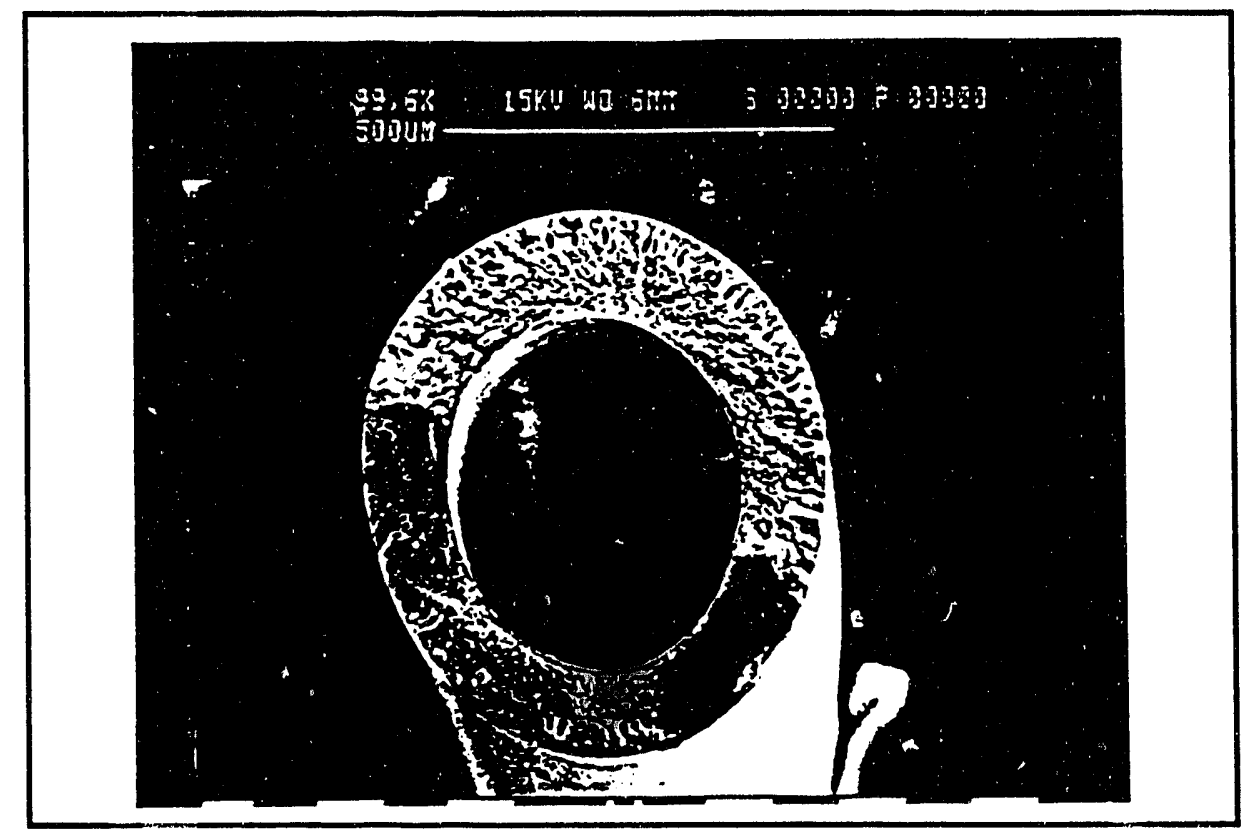

Figure 2. SEM of the Cross Section of a Polymer B Fiber

\section{III.C. EVALUATION OF HOLLOW FIBERS}

\section{III.C.1. Effects of Solvent Exposure}

When operated on oily waste waters, the hollow fibers will be exposed to a wide variety of solvents. The purpose of this task was to evaluate the effects of solvent exposure on the burst pressure of the fibers.

The procedure used in this task was as follows. Samples of the hollow fibers were soaked in various solvents for 72 hours at room temperature. The fibers were then removed from the solvent and pressurized with water until they burst.

As the results in Table VI show, the burst pressure of the initial Polymer A fibers declined after exposure to each of the solvents tested. Indeed, these fibers dissolved or swelled excessively when exposed to DMAC and NMP. This was also true for a fiber made from PES-a polymer we used to make our conventional non-solvent-resistant hollow fibers. 
Table VI. Effect of Solvent Exposure on Fiber Burst Pressure

Conditions: Fibers soaked for 72 hours in solvent at room temperature

Burst Pressure (atm)

\begin{tabular}{lcccc}
\cline { 2 - 5 } \multicolumn{1}{c}{ Solvent } & $\begin{array}{c}\text { Polymer A } \\
\text { (Initial) }\end{array}$ & $\begin{array}{c}\text { Polymer A } \\
\text { (Improved) }\end{array}$ & Polymer B & PES \\
\hline None & 12 & 38 & 43 & 23 \\
Toluene & 14 & 30 & 38 & 12 \\
Gasoline & 11 & 43 & 41 & 14 \\
DMAC & Dis $^{\star}$ & 21 & 22 & Dis \\
NMP & Dis & 14 & 25 & Dis \\
Methanol & 18 & 41 & 37 & 18 \\
Ethanol & 19 & 39 & 42 & 25 \\
Acetone & 16 & 33 & 32 & Dis \\
\hline
\end{tabular}

"Dis = dissolved or softened.

However, the burst pressures for the improved Polymer A fibers and the Polymer B fibers showed little or no decline, indicating these fibers are solvent-resistant. Based on these data, the solvent-resistant hollow-fiber supports should be suitable for operation on oily waste waters that contain solvents.

\section{III.C.2. Effects of Temperature}

As indicated in Table I, we set a target burst pressure of 28 atm for the fibers at a temperature of $60^{\circ} \mathrm{C}$. Many of oily water streams have temperatures above $40^{\circ} \mathrm{C}$, and some approach temperatures of $60^{\circ} \mathrm{C}$. To ensure reliable operation, fibers with high burst pressures at elevated temperatures are required.

To evaluate the effect of temperature on the hollow fibers, the fiber was placed into a chamber kept at a specified temperature. The burst pressure of the fiber was then measured by pressurizing the fiber with water at the desired temperature.

Table VII shows the results of our tests conducted at room temperature (e.g., $22^{\circ} \mathrm{C}$ ), $60^{\circ} \mathrm{C}$, and $90^{\circ} \mathrm{C}$. As these data show, the improved Polymer A fibers and the Polymer B fibers retained their high burst pressures at elevated temperatures. Both types of fibers had burst pressures at $60^{\circ} \mathrm{C}$ that exceeded the 28-atm target. Based on these data, we anticipate that modules made from the solvent-resistant hollow fibers will have long lifetimes when operated on high-temperature (e.g., $60^{\circ} \mathrm{C}$ ) feed streams. 
Table VII. Effect of Temperature on Fiber Burst Pressure

Burst Pressure (atm)

\begin{tabular}{cccccc}
$\begin{array}{c}\text { Temperature } \\
\left({ }^{\circ} \mathrm{C}\right)\end{array}$ & Target & $\begin{array}{c}\text { Polymer A } \\
\text { (Initial) }\end{array}$ & $\begin{array}{c}\text { Polymer A } \\
\text { (Improved) }\end{array}$ & Polymer B & PES \\
\hline 22 & -- & 23 & 38 & 43 & 23 \\
60 & 28 & 9 & 38 & 33 & 16 \\
90 & -- & 16 & 40 & 36 & 20
\end{tabular}

\section{III.D. CONCLUSIONS REGARDING DEVELOPMENT OF SOLVENT-RESISTANT} HOLLOW FIBERS

Our program to develop a solvent-resistant hollow fiber was highly successful. Fibers made from the solvent-resistant polymers met all of the target properties set for the program (see Table I). Furthermore, when these fibers were used as supports for the loose- $\mathrm{RO}$ coatings, the resulting TFC membranes had high water fluxes. 


\section{SELECTION COATING AND SCALE-UP OF MODULES}

The purpose of this work was to select the proper coating for the solvent-resistant hollow fiber supports and to then scale up this technology to larger-scale (e.g., 0.1 to $1 \mathrm{~m}^{2}$ ) modules. The results of our work in this task area follow.

\section{IV.A. SELECTION OF COATING}

The purpose of this work was to select the coating used on the inside (lumen) surfaces of the solvent-resistant hollow-fiber supports. We began our work with Polymer A, producing "initial" Polymer A fibers, and then modified the fiber-spinning spinning conditions to improve the strength and solvent resistance of these fibers. The resulting fibers were designated "improved" Polymer A fibers. The modified fiber-spinning conditions were used to spin all Polymer B fibers. This coating needed to be solvent-resistant and selective, allowing water to pass freely through the wall of the membrane but restricting transport of oil and grease and some of the dissolved organics and salts in the feed. For these tests, we made small-scale modules that contained the solvent-resistant fibers described in Section III. These modules each contained about 20 fibers and had an effective membrane area of about $0.01 \mathrm{~m}^{2}$.

Once the modules were made, the lumen surfaces of the fibers were coated "loose RO" TTM coatings. This patented series of coatings was developed previously in a DOE program (McCray et al., 1988; McCray, 1989). Four different thin coatings were applied: TTM-60, TTM-40, TTM-30, and TTM-20. The modules were tested on two types of feed solutions, one containing $5000 \mathrm{ppm} \mathrm{MgSO} 4$ and one containing $175 \mathrm{ppm}$ oil and grease. As the data in Table VIII shows, a wide range of salt rejections is possible with the TTM coatings.

Table VIII. Performance of Modules Containing Fibers Coated With TTM Coatings

\begin{tabular}{cccc} 
Coating & \multicolumn{2}{c}{ MgSO $_{\mathbf{4}}$ Test* $^{*}$} & Oily-Water Test $^{* *}$ \\
\cline { 2 - 5 } Type & $\begin{array}{c}\text { Flux } \\
\left(\mathbf{L} / \mathrm{m}^{2} \text {-hr) }\right.\end{array}$ & $\begin{array}{c}\text { Rejection } \\
(\%)\end{array}$ & $\begin{array}{c}\text { Permeate Oil and } \\
\text { Grease (ppm) }\end{array}$ \\
\hline TTM-60 & 29 & 98 & 4 \\
TTM-40 & 37 & 92 & 4 \\
TTM-30 & 41 & 87 & 10 \\
TTM-20 & 54 & 83 & 21 \\
\hline
\end{tabular}

* Test conditions: $7.8 \mathrm{~atm}, 5000 \mathrm{ppm} \mathrm{MgSO} 4,25^{\circ} \mathrm{C}, \mathrm{pH} 6$

** Test conditions: $7.8 \mathrm{~atm}, 175 \mathrm{ppm}$ oil and grease, $25^{\circ} \mathrm{C}, \mathrm{pH} 6$ 
In addition, all of the TTM coatings except the TTM-20 coating produced a permeate containing less than $10 \mathrm{ppm}$ oil and grease. These tests indicate that the coatings should effectively treat oily waste water. Further evaluation of coatings was performed during the field test (see Section V).

\section{IV.B. FABRICATION AND TESTING OF LARGE-SCALE MODULES}

The purpose of this work is to make and test large-scale modules using the solventresistant support fibers developed in this program. In this task, we made modules containing $0.1 \mathrm{~m}^{2}$ of membrane area to evaluate the effectiveness of our module-making procedures. We then made modules containing $1 \mathrm{~m}^{2}$ of membrane area.

Once the modules were made, the (lumen) surfaces of the fibers were coated with the TTM coatings discussed above. To accomplish this, we used a semi-automatic coating apparatus available at AquaAir Environmental, Inc. (Bend, Oregon). This company, a spin-off of Bend Research, manufactures non-solvent-resistant hollow-fiber modules and membrane systems for environmental applications. The semi-automatic coating apparatus was previously developed at Bend Research for coating modules containing up to $8 \mathrm{~m}^{2}$ of membrane area.

Details of our work with the $0.1-$ and $1-\mathrm{m}^{2}$ modules follow.

\section{IV.B.1. Tests with 0.1- $\mathrm{m}^{2}$ Modules}

Table IX shows the results of preliminary evaluations of the $0.1-\mathrm{m}^{2}$ modules on various feed solutions. As these data show, these modules performed as well as the small-scale (e.g., $0.01-\mathrm{m}^{2}$ ) modules made earlier in this program (Table VIII).

Table IX. Results of Evaluations of $0.1-\mathrm{m}^{2}$ Modules

Test Conditions: $7.8 \mathrm{~atm}, 25^{\circ} \mathrm{C}, \mathrm{pH} 6,2000 \mathrm{ppm}$ salt

\begin{tabular}{|c|c|c|c|c|c|}
\hline \multirow[b]{2}{*}{ Module } & \multirow[b]{2}{*}{$\begin{array}{c}\text { Coating } \\
\text { Type }\end{array}$} & \multicolumn{2}{|c|}{$2000 \mathrm{ppm} \mathrm{MgSO}_{4}$} & \multicolumn{2}{|c|}{2000 ppm NaCl } \\
\hline & & $\begin{array}{c}\text { Flux } \\
\left(\mathrm{L} / \mathrm{m}^{2} \cdot \mathrm{hr}\right)\end{array}$ & $\begin{array}{c}\text { Rejection } \\
(\%)\end{array}$ & $\begin{array}{c}\text { Flux } \\
\left(\mathrm{L} / \mathrm{m}^{2} \cdot \mathrm{hr}\right)\end{array}$ & $\begin{array}{c}\text { Rejection } \\
(\%)\end{array}$ \\
\hline $1110-6 \mathrm{~A}$ & TTM-60 & 43 & 92 & 47 & 39 \\
\hline $1110-6 \mathrm{~B}$ & TTM-60 & 89 & 97 & 94 & 38 \\
\hline 1091-77B & TTM-40 & 100 & 93 & $\mathrm{NM}^{*}$ & NM \\
\hline $1091-78 A$ & TTM-40 & 60 & 92 & NM & NM \\
\hline 1091-77A & TTM-40 & 52 & 66 & NM & NM \\
\hline $1110-7 \mathrm{~A}$ & TTM-20 & 100 & 73 & 100 & 19 \\
\hline $1110-7 \mathrm{~B}$ & TTM-20 & 105 & 67 & 105 & 18 \\
\hline
\end{tabular}

*NM $=$ not measured

To evaluate the effectiveness of these modules for treating oily-water solutions, we operated Module 1091-77B on a feed solution containing about $600 \mathrm{ppm}$ oil and grease.

Figure 3 shows the water flux through the module as a function of time for the test, which lasted 


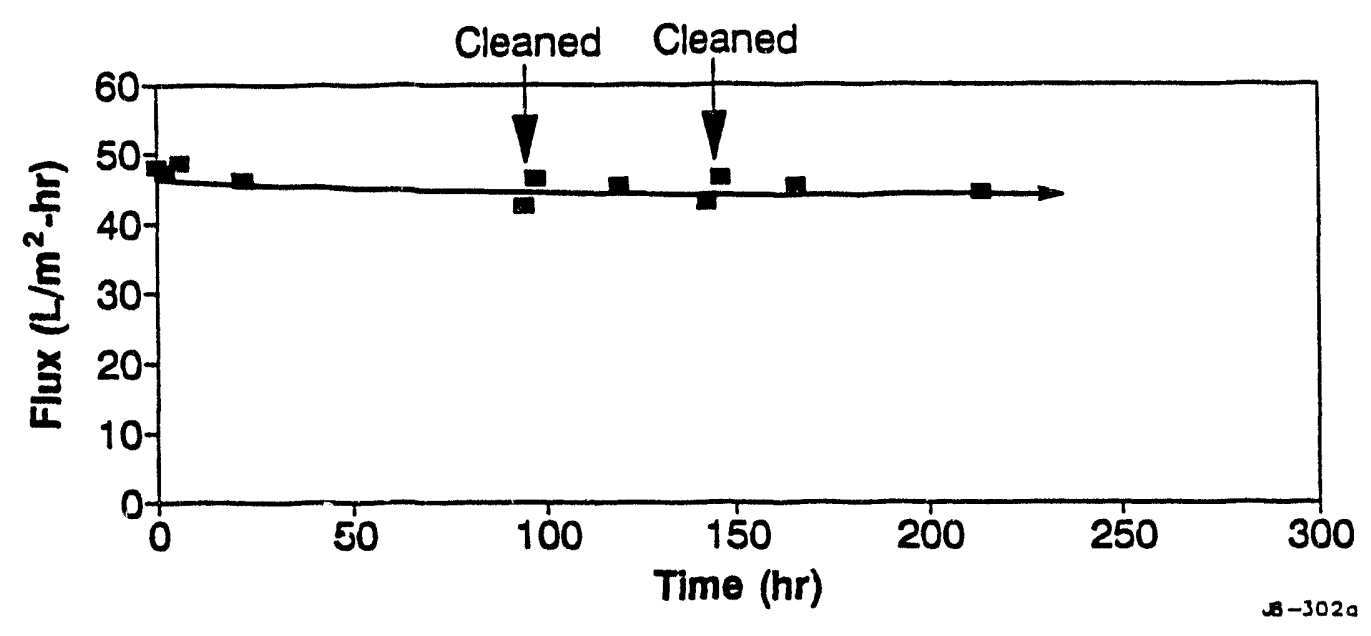

Figure 3. Flux as a Function of Time for Module 1091-77B $\left(0.1 \mathrm{~m}^{2}\right)$ Operating on Synthetic Oily Water

Test Conditions: $600 \mathrm{ppm}$ oil and grease, $4.5 \mathrm{~atm}, 22^{\circ} \mathrm{C}$

more than 200 hours. As these data show, the performance of the module remained nearly constant during the test.

Figure 4 shows the concentration of oil and grease in the feed and permeate during this test. As these data show, the module rejected more than $99 \%$ of the oil and grease. Indeed, the concentration of oil and grease in the permeate was less than $5 \mathrm{ppm}$ during the test.

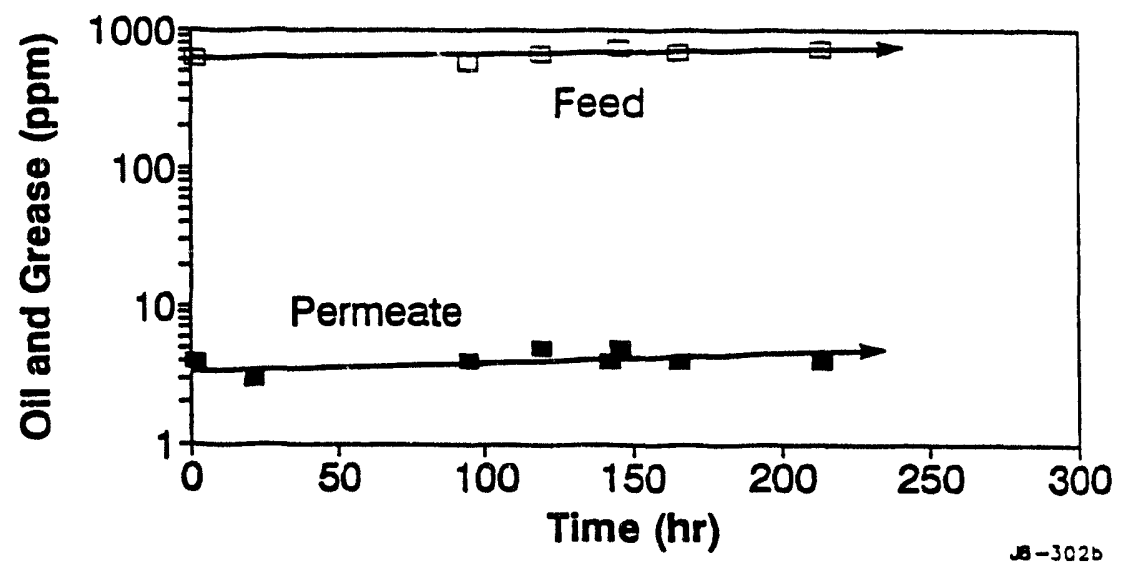

Figure 4. Feed and Permeate Concentrations of Oil and Grease for Module 1091-778 $\left(0.1 \mathrm{~m}^{2}\right)$ Operating on Synthetic Oily Water

Test Conditions: $600 \mathrm{ppm}$ oil and grease, $4.5 \mathrm{~atm}, 22^{\circ} \mathrm{C}$ 
We also examined how cleaning procedures affect the performance of the module. As shown in Figure 3, the modules were cleaned twice during the test-once at 100 hours and once at 140 hours. Performance did not change significantly after the modules were cleaned.

\section{IV.B.2. Tests with $1-\mathrm{m}^{2}$ Modules}

Table X shows the results of preliminary evaluations of the $1-\mathrm{m}^{2}$ modules under our standard evaluation conditions. As these data show, these modules perform as well as the smaller-scale modules (i.e., modules containing $0.01 \mathrm{~m}^{2}$ and $0.1 \mathrm{~m}^{2}$ of membrane made earlier in this program [see Tables VIII and IX, respectively]).

Table X. Performance of Large-Scale (1- $\left.\mathrm{m}^{2}\right)$ TTM-40 Modules Test Conditions: $7.8 \mathrm{~atm}, 25^{\circ} \mathrm{C}, 2000 \mathrm{ppm} \mathrm{MgSO} 4, \mathrm{pH} 6$

\begin{tabular}{ccccc} 
& \multicolumn{2}{c}{ Initial Test } & \multicolumn{2}{c}{ After Pressure-Cycling* } \\
\cline { 2 - 5 } Module No. & $\begin{array}{c}\text { Water Flux } \\
\left(\mathbf{L m}^{2} \text {-hr }\right)\end{array}$ & $\begin{array}{c}\mathbf{M g S O}_{\mathbf{4}} \text { Rejection } \\
(\%)\end{array}$ & $\begin{array}{c}\text { Water Flux } \\
\left(\mathbf{L} / \mathbf{m}^{2} \text {-hr }\right)\end{array}$ & $\begin{array}{c}\text { MgSO }_{\mathbf{4}} \text { Rejection } \\
(\%)\end{array}$ \\
\hline Target & $>34$ & $>85$ & -- & -- \\
SR-1 & 34 & 89 & 43 & 73 \\
SR-2 & 65 & 93 & 53 & 88 \\
SR-3 & 34 & 85 & 46 & 89 \\
\hline
\end{tabular}

"Pressure-cycling conditions: 14 atm for 1 minute, 1 atm for 1 minute Modules SR-1 and SR-3 were cycled 900 times. Module SR-2 was cycled 400 times.

The data in Table $\mathrm{X}$ also show the performance of the modules after cycling them to $14 \mathrm{~atm}$ for 400 to 900 cycles. As these data show, the performance of Module SR-2 and Module SR-3 changed only slightly, demonstrating the robustness of these modules. However, the salt rejection of Module SR-1 declined. We believe this loss in salt rejection was caused by damage to the fibers during the modularization process. Based on these results, Module SR-2 and Module SR-3 were selected for use in the demonstration tests.

\section{IV.C. CONCLUSIONS REGARDING COATING SELECTION AND MODULE SCALE-UP}

Our work showed that the TTM coatings will work well for the treatment of oily waters. The TTM-60, TTM-40, and TTM-30 coatings are particularly suitable because they result in high water fluxes and high rejections of oil and grease. These coatings were also incorporated into large-scale (e.g., $0.1-$ and $1-\mathrm{m}^{2}$ ) modules.. The performance of the large-scale modules was approximately the same as that of the small-scale modules, indicating that the procedures used to scale up the technology worked well. 


\section{FIELD TESTING}

The primary objective of this program was to field-test the solvent-resistant module technology. This objective was achieved. Several preliminary field tests were performed using the $0.1-\mathrm{m}^{2}$ modules described in Section IV. In addition, using resources and a demonstration unit owned and operated by AquaAir Environmental, a field test was performed using the $1-\mathrm{m}^{2}$ modules and modules provided by AquaAir Environmental. Details of our work follow.

\section{V.A. PRELIMINARY FIELD TESTS}

Three preliminary field tests of the $0.1-\mathrm{m}^{2}$ modules described in Section IV.C.1. were performed in this program In these tests, approximately 20 liters of oily waste water was obtained for use as the feed solution. This feed solution was then fed to the hollow-fiber module using a small circulation pump, as shown in Figure 5. As clean permeate was removed from the feed solution (i.e., as recovery increased), the concentration of contaminants in the feed solution increased. Steps were taken during these tests to reduce or eliminate exposure of the feed stream to oxygen. Thus, these tests were designed to simulate the actual operating conditions to which the membranes would be exposed in a continuous process.

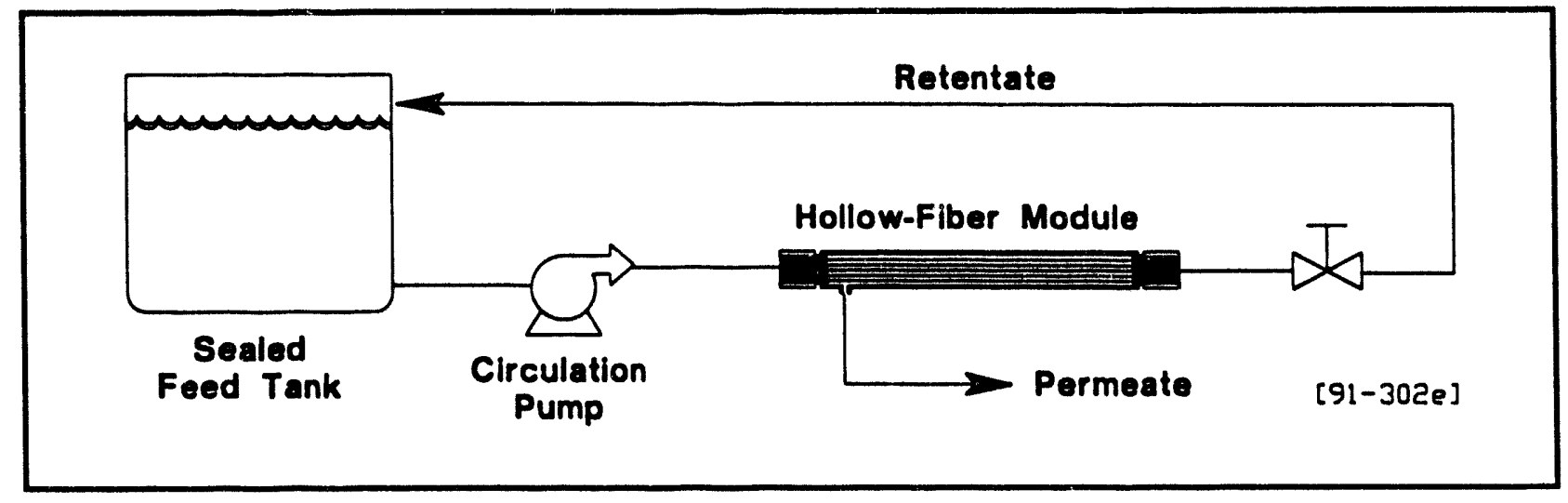

Figure 5. Schematic of Test Loop Used During Preliminary Field Tests

Table XI summarizes these preliminary field tests. In the first test, conducted on an offshore platform near Santa Barbara, California, the modules produced a permeate contrining $28 \mathrm{ppm}$ oil and grease. This represented a rejection for oil and grease of $88 \%$. Unfortunately, the flux through the membrane was only about $5 \mathrm{~L} / \mathrm{m}^{2}-\mathrm{hr}$. We believe the low flux was due to the presence of additives that are used to improve the performance of the induced-gas-flotation (IGF) unit that is normally used to treat the oily water generated on this platform. 
Table XI. Summary of Preliminary Field Tests

\begin{tabular}{|c|c|c|c|c|c|}
\hline Test Site & Module Type & $\begin{array}{l}\text { Feed Oll and } \\
\text { Grease } \\
\text { (ppm) }\end{array}$ & $\begin{array}{l}\text { Permeate Oll } \\
\text { and Grease } \\
\text { (ppm) }\end{array}$ & $\begin{array}{c}\text { Oll and Grease } \\
\text { Rejection } \\
(\%) \\
\end{array}$ & $\begin{array}{l}\text { Water Flux } \\
\left(\mathrm{L} / \mathrm{m}^{2}-\mathrm{hr}\right)\end{array}$ \\
\hline $\begin{array}{l}\text { Santa Barbara, } \\
\text { California }\end{array}$ & $T T M-40$ & 250 & 28 & 88 & $\sim 5$ \\
\hline $\begin{array}{l}\text { Friendswood, } \\
\text { Texas }\end{array}$ & TTM-20 & 350 & 5 & 98 & 37 \\
\hline $\begin{array}{l}\text { Grand Isle, } \\
\text { Louisiana }\end{array}$ & $\pi M-40$ & 280 & 7 & 98 & 34 \\
\hline
\end{tabular}

As the data in Table XI show, we obtained much better results in subsequent field tests. Figure 6 shows the water flux and concentration of oil and grease in the permeate as functions of recovery for a TTM-20 module operating on the feed solution for a test at Friendswood, Texas. In this case, the module rejected $98 \%$ of oil and grease, producing a permeate that contained less than $10 \mathrm{ppm}$ oil and grease at recoveries up to $99 \%$. The data in Figure 6 also show that the TTM-20 module maintained a high flux-37 L/m $\mathrm{m}^{2}-\mathrm{hr}$-during this test.

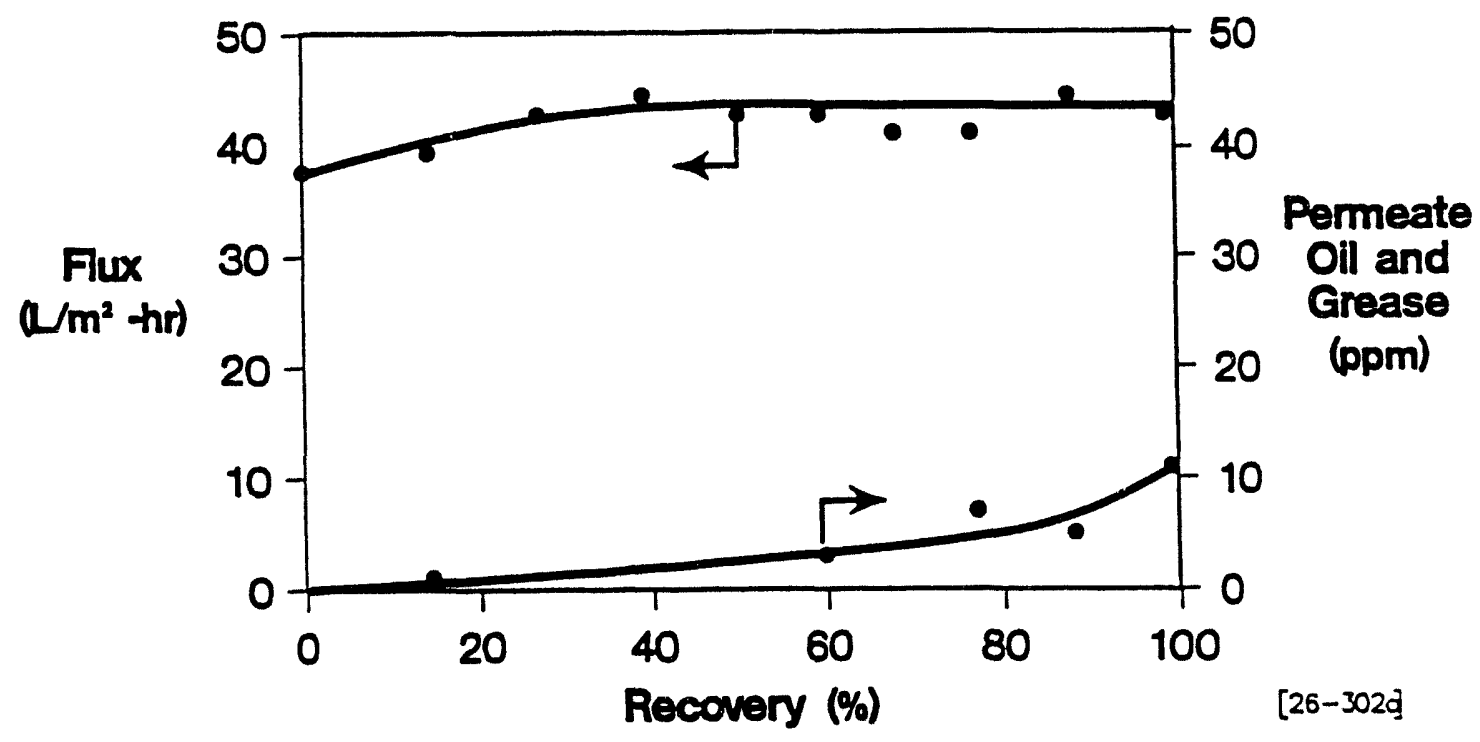

Figure 6. Performance of TTM-20 Hollow-Fiber Module During Preliminary Field Tests at Friendswood, Texas

Test Conditions: Water from bottom of free-water knockout tank, 5-atm inlet pressure, $40^{\circ} \mathrm{C}$

Feed oll and grease: $350 \mathrm{ppm}$ 
Similar results were obtained during tests at Grand Isle, Louisiana, this time using a TTM-40 module. In those tests, the modules rejected more than $98 \%$ of the oil and grease while maintaining high flux.

\section{V.B. DEMONSTRATION FIELD TEST}

Figure 7 shows a schematic of the demonstration unit used to perform the demonstration field test at a site near Friendswood, Texas. This unit, owned and operated by AquaAir Environmental, was designed to test technology currently under development by AquaAir, as well as the improved, solvent-resistant technology that is the focus of this program.

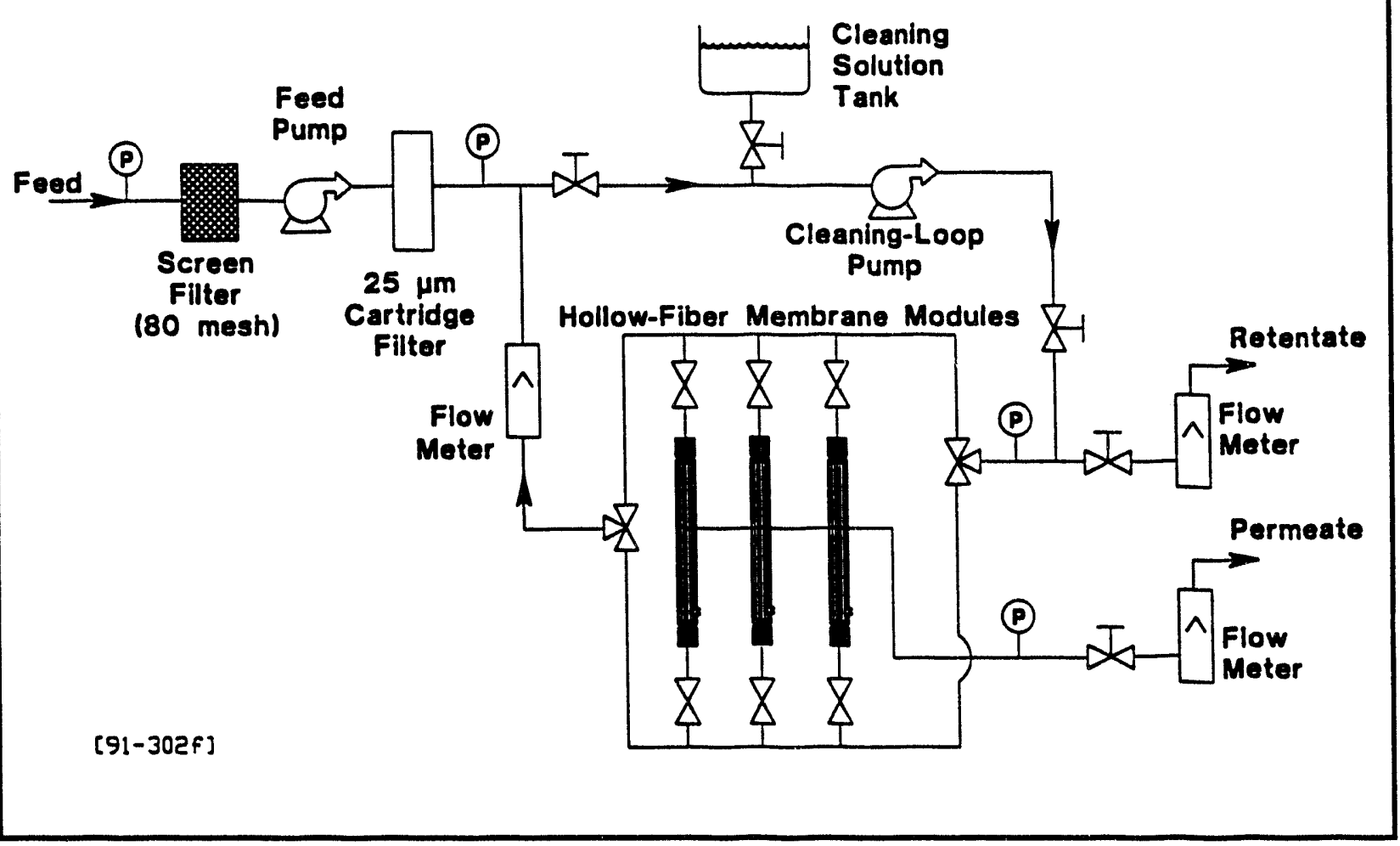

Figure 7. Demonstration Unit

During the field tests, parametric and long-term tests were performed. These results are described below. 


\section{V.B.1. Parametric Tests}

The first parametric test performed with the demonstration unit was designed to compare the performance of the TTM- 20 and TTM- 60 coatings when operated on oily water. Figure 8 shows the results of this test. In this test, the feed stream contained approximately $1,000 \mathrm{ppm}$ oil and grease and approximately 10,000 ppm salts. The permeate from each module tested contained less than $7 \mathrm{ppm}$ oil and grease-an oil and grease rejection of $99.3 \%$. The permeate was of sufficient quality to meet all known discharge regulations in the Gulf Coast area.

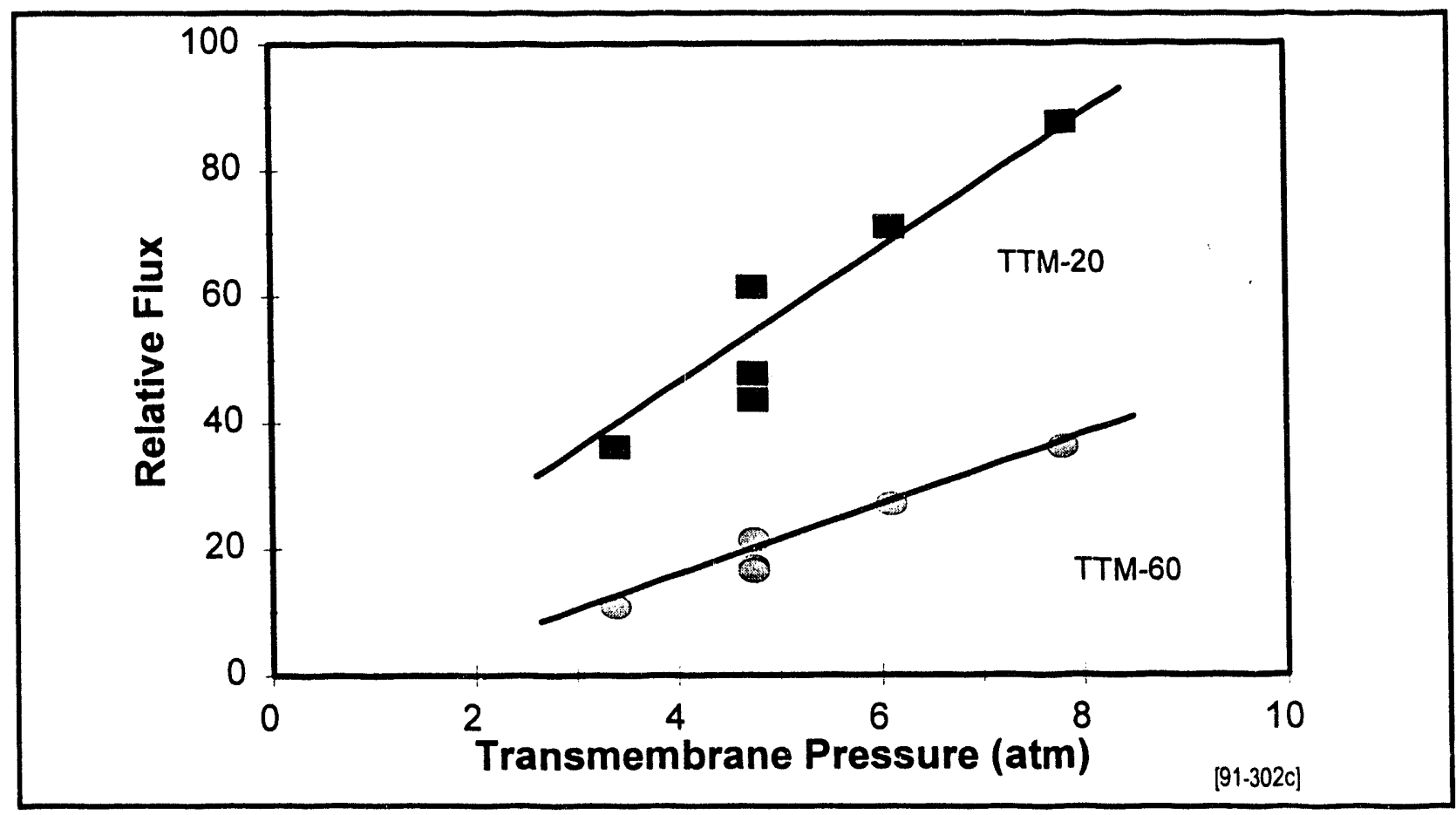

Figure 8. Relative Water Flux Versus Transmembrane Pressure for TTM-20 and TTM-60 Hollow-Fiber Modules

Test Conditions: Feed: $\sim 10,000 \mathrm{ppm}$ salts (mostly $\mathrm{Ca}^{+2}$ ), $\sim 1,000 \mathrm{ppm}$ oil and grease Permeate: $<7$ ppm oil and grease

As expected, the flux through the modules increased with pressure. The module containing fibers with the TTM-20 coating had a significantly higher flux than the module with the TTM- 60 coating. We believe two factors contributed to the higher flux of the TTM-20 module. First, the TTM-20 coating has a higher water permeability than the TTM- 60 coating. This means that at the same operating pressure, the flux through the TTM-20 module will be higher than that through the TTM-60 module. 
Second, the TTM-20 module has a lower rejection for dissolved salts than does the TTM-60 module. This means that the osmotic-pressure difference across the TTM-20 module will be lower than that across the TTM-60 module, as illustrated in Figure 9. This results in a higher net driving force for the TTM-20 module and a correspondingly higher water flux.

\section{Conventional RO Membrane}

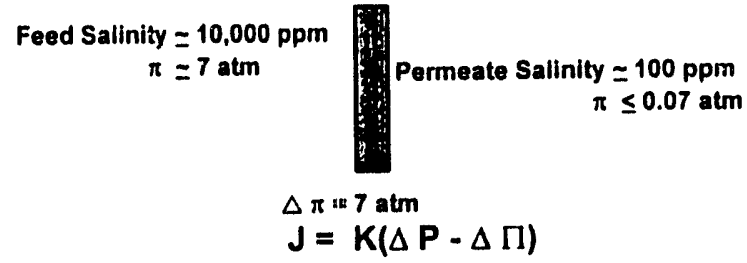

TTM-20

Feed Salinity $\equiv 10,000 \mathrm{ppm}$ $\pi \pm 7$ atm

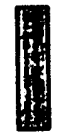

$\Delta \pi=1.4 \mathrm{~atm}$ $J=K(\Delta P-\Delta[I)$
Permeate Sallnity $\approx 8000$ ppm $\pi \leq \mathbf{5 . 6} \mathrm{atm}$

\section{Fod}

Feed Salinity $\approx 10,000$ ppm $\pi \approx 7 \mathrm{~atm}$
$\pi \approx 10,000$ TTM-60

pm Permeate Salinity - 5000 ppm $\pi=35 \mathrm{~atm}$ $\Delta \pi=3.5 \mathrm{~atm}$ $J=K(\Delta P \cdot \Delta \pi)$ [91-3021]

Figure 9. Effect of Osmotic F'ressure on Membrane Performance

$$
\text { Key: } \begin{aligned}
\pi & =\text { osmotic pressure } \\
K & =\text { water permeability } \\
& =\text { water fluik } \\
& P=\text { operating pressure }
\end{aligned}
$$

Figure 10 shows the water permeability of the membrane plotted versus transmembrane pressure. As these data show, the water permeability was not affected by transmembrane pressure during these tests. This was as expected based on our previous studies with the TTM-60 and TTM-20 membranes. These data indicated that, when operated on an oily water feed, the performance of the membranes should be similar to that of modules in our laboratory "control" tests on oily-water feeds. 


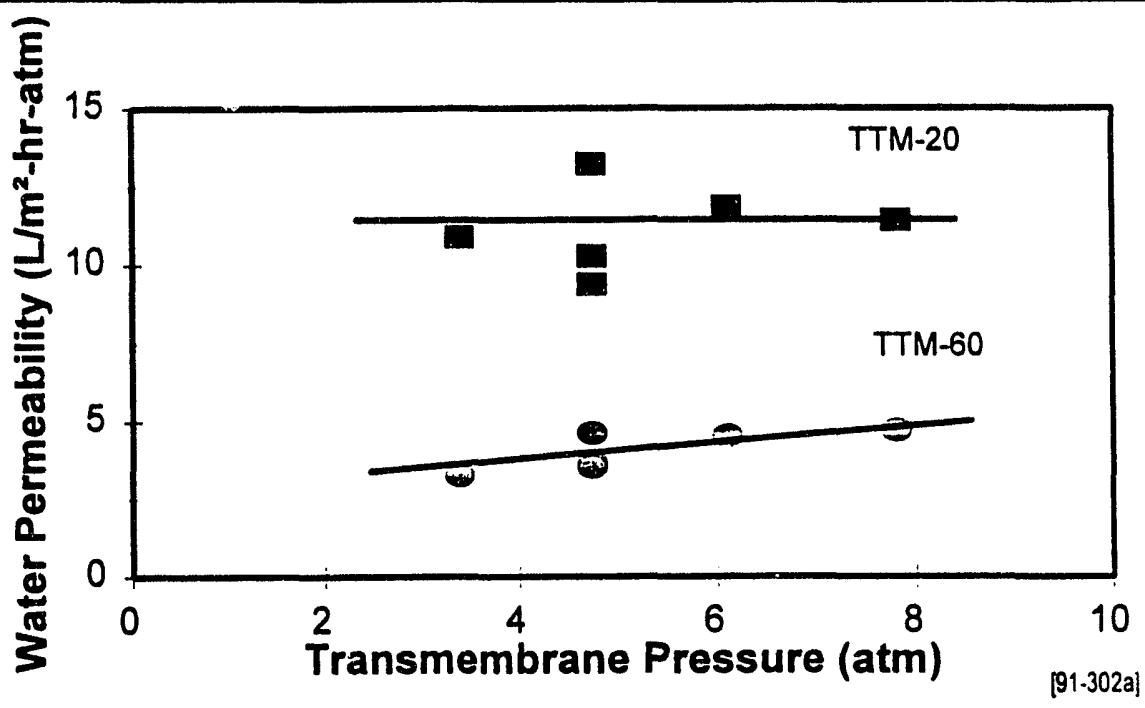

Figure 10. Water Permeability Versus Transmembrane Pressure for TTM-20 and TTM-60 Hollow-Fiber Modules

Test Conditions: Feed: $\sim 10,000$ ppm salts (mostly $\mathrm{Ca}^{+2}$ ), $\sim 1,000 \mathrm{ppm}$ oil and grease Permeate: $<7$ ppm oil and grease

Figure 11 shows the water permeability of the membranes plotted versus time. As the data show, the flux of the TTM-20 module declined slightly - likely due to a build-up of a layer of oil on the surface of the membrane. This was expected. The water flux stabilized at a water permeability of approximately $0.4 \mathrm{gal} / \mathrm{ft}^{2}$-day- $100 \mathrm{psi}$.

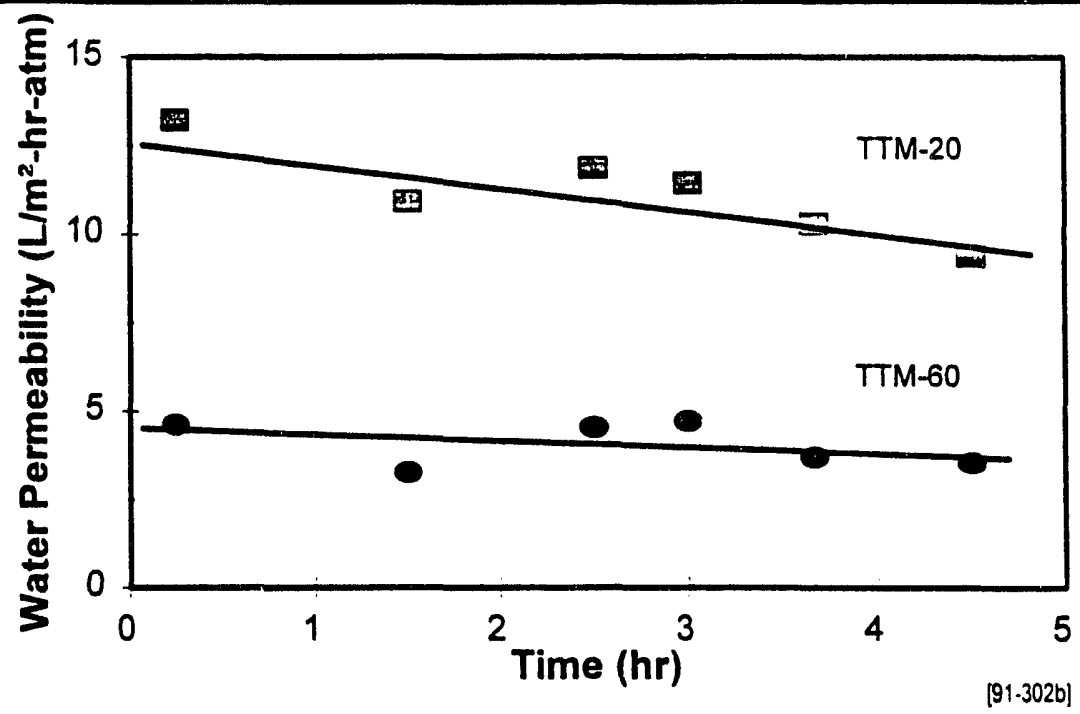

Figure 11. Water Permeability Versus Time for TTM-20 and TTM-60 Hollow-Fiber Modules

Test Conditions: Feed: $\sim 10,000$ ppm salts (mostly $\mathrm{Ca}^{+2}$ ), $\sim 1,000 \mathrm{ppm}$ oil and grease Permeate: $<7 \mathrm{ppm}$ oil and grease 


\section{V.B.2. Long-Term Tests}

To perform the long-term tests, three large-scale modules made by AquaAir Environmental were installed on the system and operated in parallel. The demonstration unit was then operated for more than 2000 hours.

During the long-term tests, the modules were operated continuously without an operator at the test site. Data were collected by a remote sensing package and transmitted to computer located off-site. Periodically, the data were examined by a technician and at least once a week an operator traveled to the test site to ensure all systems were operating properly. The advantage of this type of operation is that the costs are very low. However, it allows only limited control over the system, and it is difficult to take corrective measures promptly.

Figure 12 shows the water flux through the hollow-fiber modules as a function of time during the demonstration test. As these data show, flux varied significantly during the test. The reasons for this variation in flux are described below.

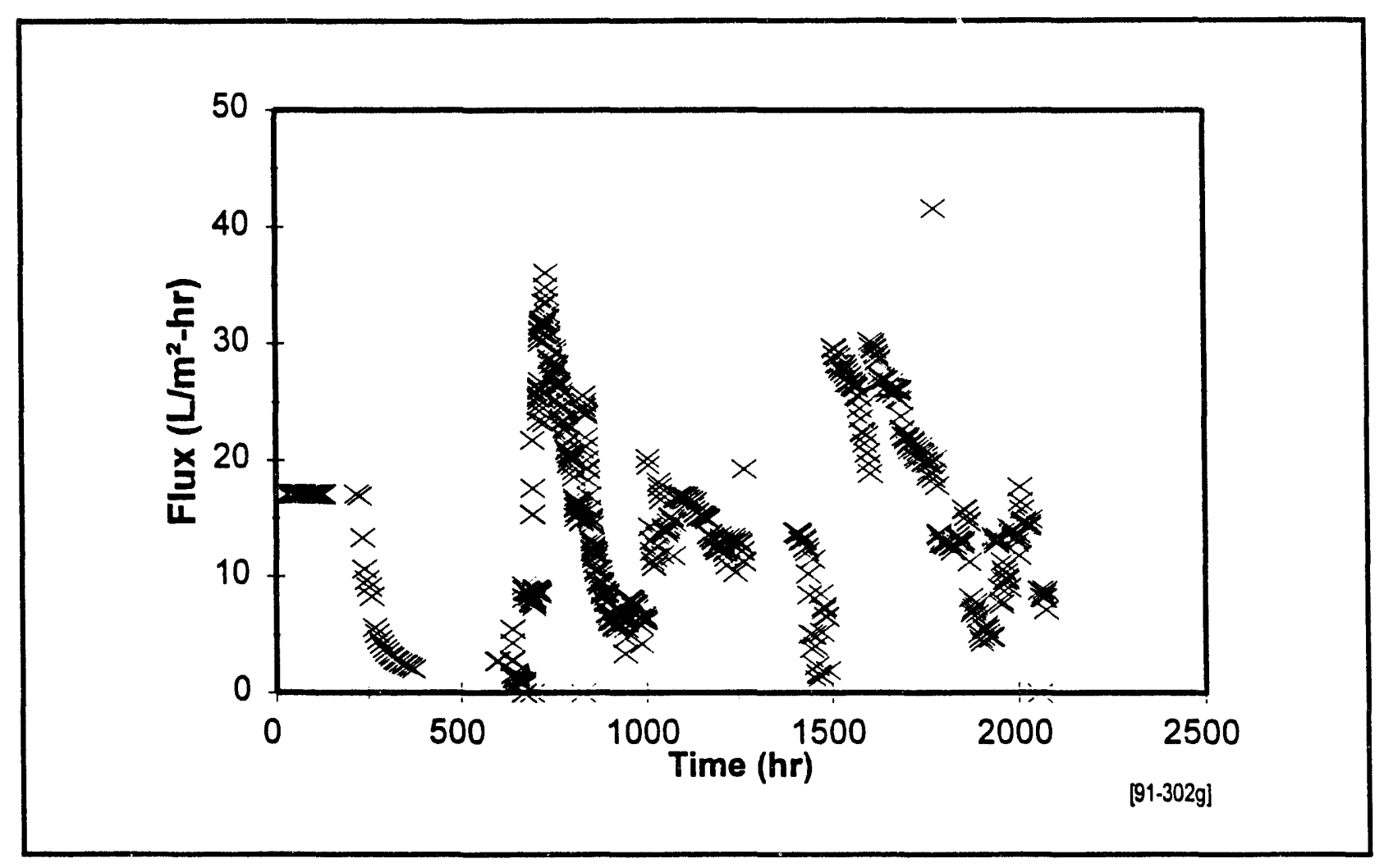

Figure 12. Water Flux as a Function of Time for the Demonstration Unit 
First, the data in Figure 12 show that initially (during the first 200 hours), the flux through the modules remained constant at $17 \mathrm{~L} / \mathrm{m}^{2}$-hr-atm. This was because 1) the feed solution did not change appreciably over this time period, and 2) the operating conditions were adjusted to produce constant flux.

However, at about 200 hours, a surge of scale-forming contaminants entered the system. This led to scale formation on the membrane surface and a corresponding loss in flux. The reason for the loss in flux was not identified until about 600 hours; the modules were then cleaned with an acid solution to remove the scale. This cleaning restored the flux through the membrane.

The data in Figure 12 show that after cleaning (at about 700 hours), the flux through the membrane again decreased. This was due to variations in feed-flow rate, as shown in Figure 13. Indeed, at about 750 hours, the feed-flow rate to the modules accidentally dropped to 0 , leading to $100 \%$ recovery in the system (Figure 14). These operating conditions led to the formation of a concentrated layer of oil on the membrane surface and a subsequent loss in flux. However, when the feed-flow rate was restored to the original value (about $38 \mathrm{~L} / \mathrm{min}$ ), the flux stabilized.

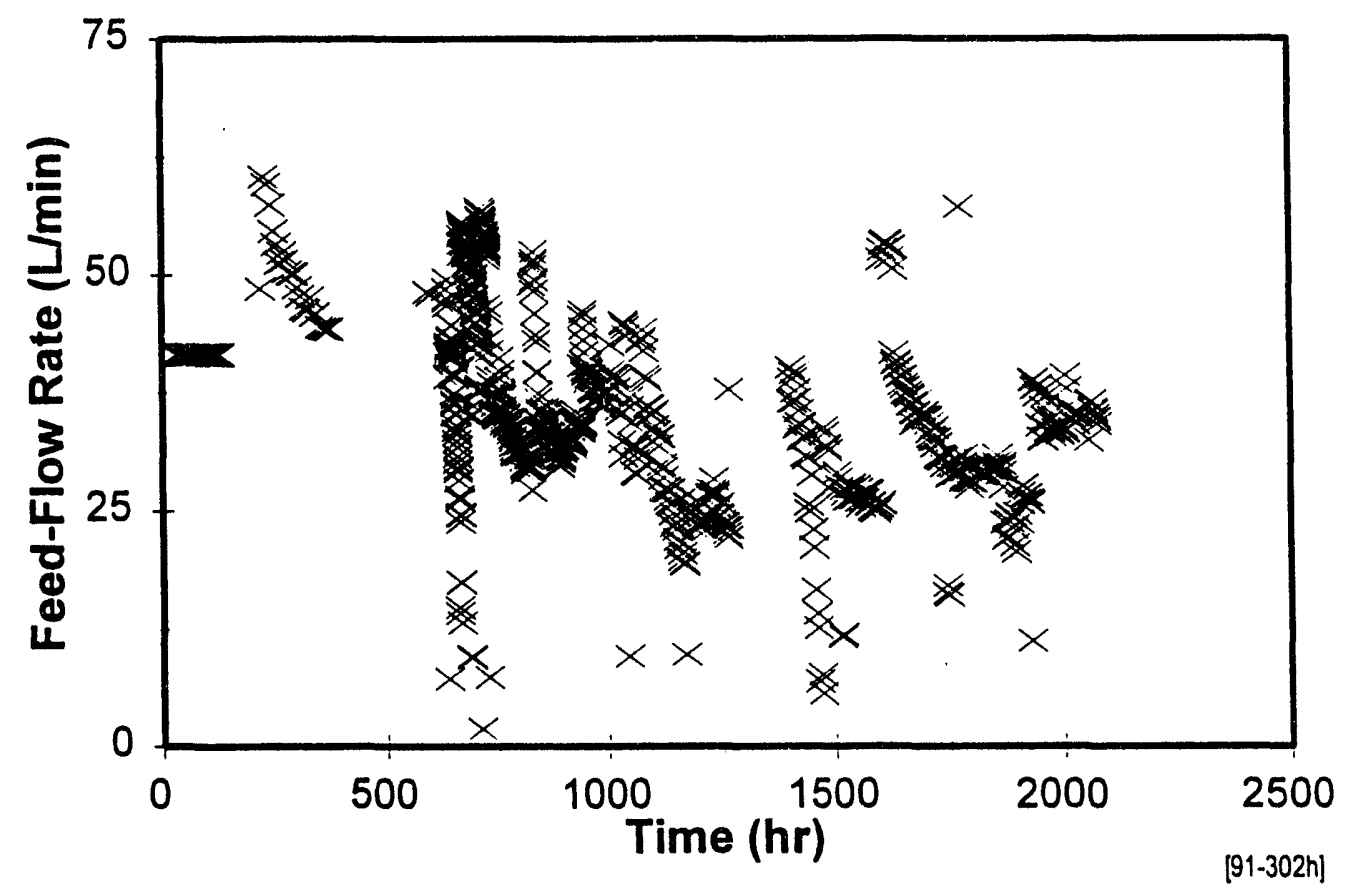

Figure 13. Feed-Flow Rate as a Function of Time During the Demonstration Test 


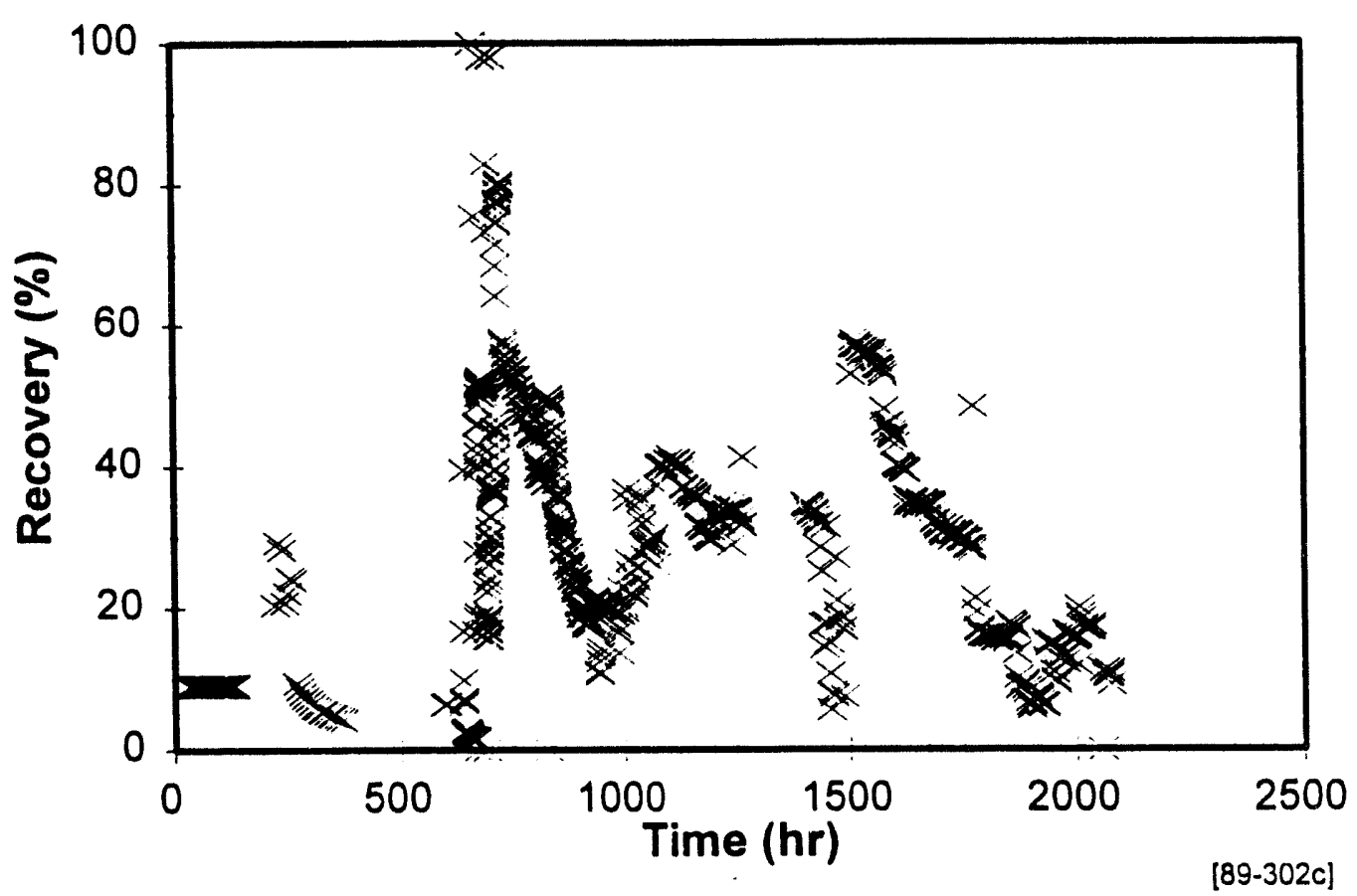

Figure 14. Water Recovery as a Function of Time During the Demonstration Unit

At about 1400 hours of operation, a high concentration of silt entered the system, plugging the prefilters. This led to a decrease in feed-flow rate and a subsequent loss in flux. Silt remained a problem for the remainder of the test, leading to erratic flow rates and fluxes.

Periodically during the long-term test, samples of the permeate stream were analyzed for oil and grease. In all cases, the permeate contained less than $10 \mathrm{ppm}$ oil and grease. This is less than all known discharge regulations.

\section{V.C. CONCLUSIONS REGARDING THE FIELD TESTS}

The field tests show that the technology developed in this program offers an attractive alternative for treating oily waste waters. The hollow-fiber membranes produced a high-quality permeate-in most applications suitable for discharge. In addition, during preliminary tests, the membrane modules maintained high fluxes.

The long-term tests of the hollow-fiber membrane modules were successful in that the modules produced permeate water of sufficient quality to meet all discharge regulations. However, the fluxes through the modules varied considerably during the test due to changes in feed composition and changes in operating conditions. Based on these tests, a more extensive pretreatment system (other than coarse filtration) will be needed to make this technology commercially viable. 


\section{CONCLUSIONS AND RECOMMENDATIONS}

This program was highly successful. A new generation of hollow-fiber membranes were developed that have the chemical and thermal resistance needed for use under harsh processing conditions. This new class of membranes promises to make possible the use of membranes in the chemical process industry to perform many industrially important separations, including the treatment of oily waste water.

During this program, we used the solvent-resistant hollow fibers as supports for our loose-RO TTM coatings. Our work showed that these TTM coatings will work well for the treatment of oily waters. The TTM-60, TTM- 40 , and TTM- 30 coatings are particularly suitable because they result in high water fluxes and high rejections of oil and grease. These coatings were incorporated into large-scale $\left(0.1-\right.$ and $\left.1-\mathrm{m}^{2}\right)$ modules.. The performance of the large-scale modules was approximately the same as that of the small-scale modules, indicating that the procedures used to scale up the technology worked well.

This program culminated in a series of field tests, initially using small-scale module, and then using large-scale modules in a demonstration test. The field tests show that the technology developed in this program offers an attractive alternative for treating oily waste waters. The hollow-fiber membranes produced a high-quality permeate-that was suitable for discharge. In addition, during preliminary tests, the membrane modules maintained high fluxes.

The long-term tests of the hollow-fiber membrane modules were successful in that the modules produced a permeate water of sufficient quality to meet all discharge regulations. However, the fluxes through the modules varied considerably during the test due to changes in feed composition and changes in operating conditions. Based on this test, a more-extensive pretreatment system (other than coarse filtration) will be needed to make this technology commercially viable. Specific recommendations that would improve the performance of the system include the followin.

1. A settling system should be located upstream of the unit to prevent larger particulates from entering the system. Such a settling system would also minimize the frequency at which a prefilter would need to be changed and/or cleaned. 
2. Many oily-water treatment systems use induced-gas floatation (IGF) to remove much of the free and emulsified oil from oily waste waters. The hollow-fiber membrane technology studied here could treat the effluent from an IGF unit (which often does not meet discharge regulations), producing a permeate water that could be discharged. Furthermore, the retentate from the RO system, which contains a high concentration of oils, could be recycled back to the IGF unit, where the oil could be recovered. Such a system would minimize or eliminate the amount of liquid waste generated by the system.

3. The hollow-fiber membranes should be tested on a unit equipped with process control. This would prevent the membrane system from being operated under undesirable conditions (e.g., low feed flow).

We believe that these changes improve the performance of the membranes, particularly in regards to the water flux through the system.

As an outgrowth of this program, we are continuing development of these solvent-resistant membrane modules for a variety of applications, many of which are energy-related. The initial commercial application of these modules will likely not be for the treatment of oily waste water, since deployment of this technology in the oil and gas industry will likely be difficult without market acceptance in other industry segments. Instead, we intend to focus our initial commercialization efforts on applications in niche markets where the barriers to market entry are lower. After building industrial acceptance of our solvent-resistant membrane technology for other uses, we hope to introduce products based on the oily-water treatment technology developed in this program. 


\section{REFERENCES}

McCray, S.B., "Tetra Amido High Flux Membranes," U.S. Patent No. 4,876,009 (1989)

McCray, S.B., R.J. Ray, V.A. Burback, A.R. Chambers, W. Haley, M.H. Henry, K. Holmgren, D.J. Kelly, C.G. King, E.D. LaChapelle, A.C. Malkin, D.L. Millard, D.D. Newbold, J.R. Pledger, K.G. Plummer, and R.W. Wytcherley, "A Novel Fouling-Resistant Membrane System for Treating Oil-Field and Tar-Sand Waste Waters." Final report to the U.S. Department of Energy on Contract No. DE-AC03, 85ER80233, from Bend Research, Inc., Bend, Oregon (1988). 


\section{ACKNOWLEDGMENT}

The following Bend Research personnel contributed significantly to the content of this study.

Name

Title

\begin{tabular}{ll}
\hline S.B. McCray, Ph.D., P.E. & Principal Investigator \\
& Director, Membrane Development \\
R.J. Ray, Ph.D., P.E. & Vice President, COO \\
D.T. Friesen, Ph.D. & Director of Research \\
D.D. Newbold, M.S., P.E. & Director of Engineering \\
N.B. Gallagher, Ph.D. & Research Chemical Engineer \\
R.P. Barss & Research Chemist \\
E.D. LaChapelle & Research Chemist \\
J.R. Pledger & Laboratory Technician \\
C.L. Hostetler & Laboratory Technician \\
G.W. Campbell & Laboratory Technician \\
R.D. Cordes & Laboratory Technician \\
A.C. Malkin & Technical Editor
\end{tabular}

In addition, we would also like to acknowledge the assistance of AquaAir Environmental, who provided the demonstration unit for the testing of this technology, and assisted us in setting up and conducting the field tests. Our Phase III sponsors also assisted during the preliminary and long-term field tests described in this report. 

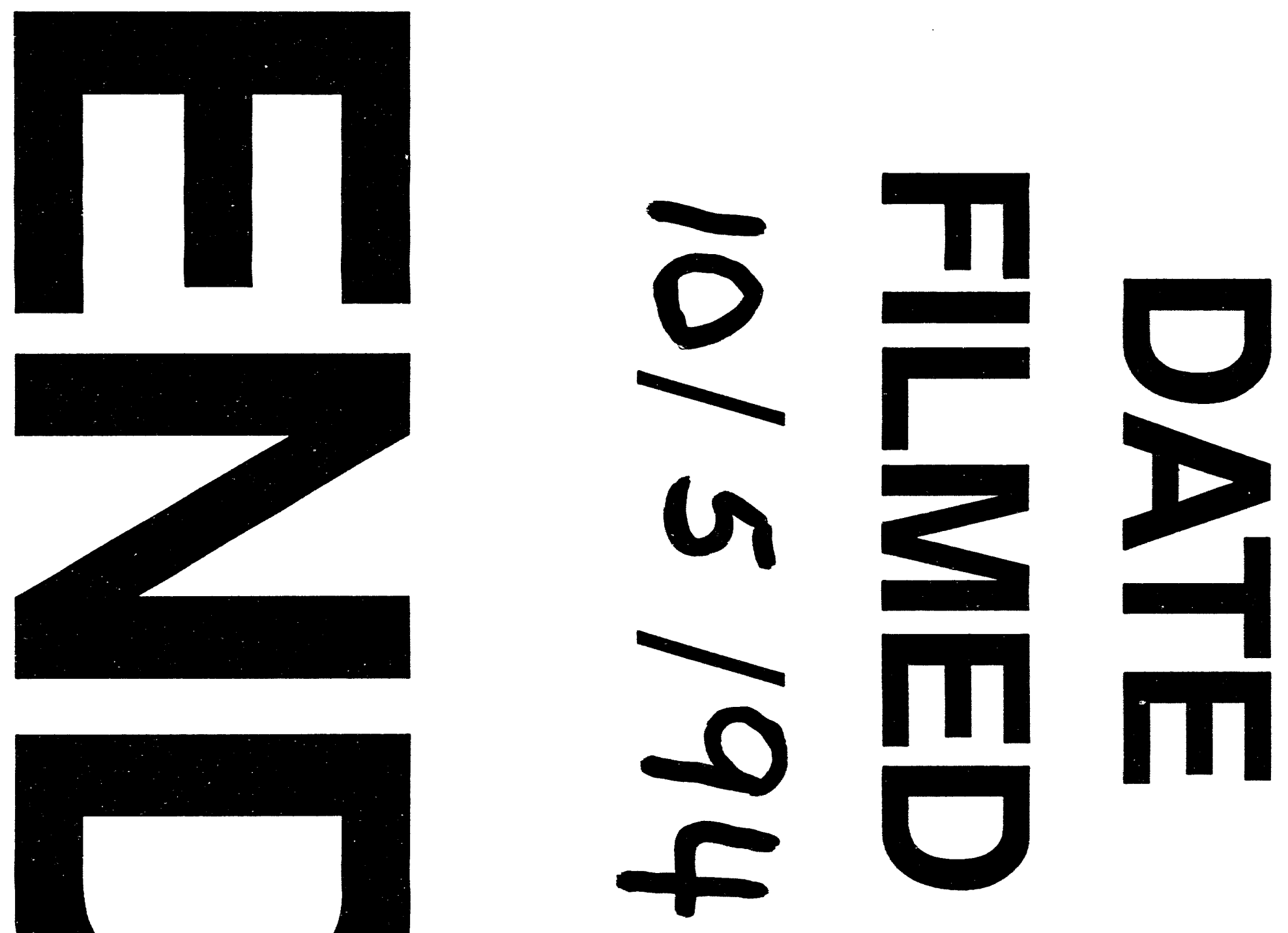


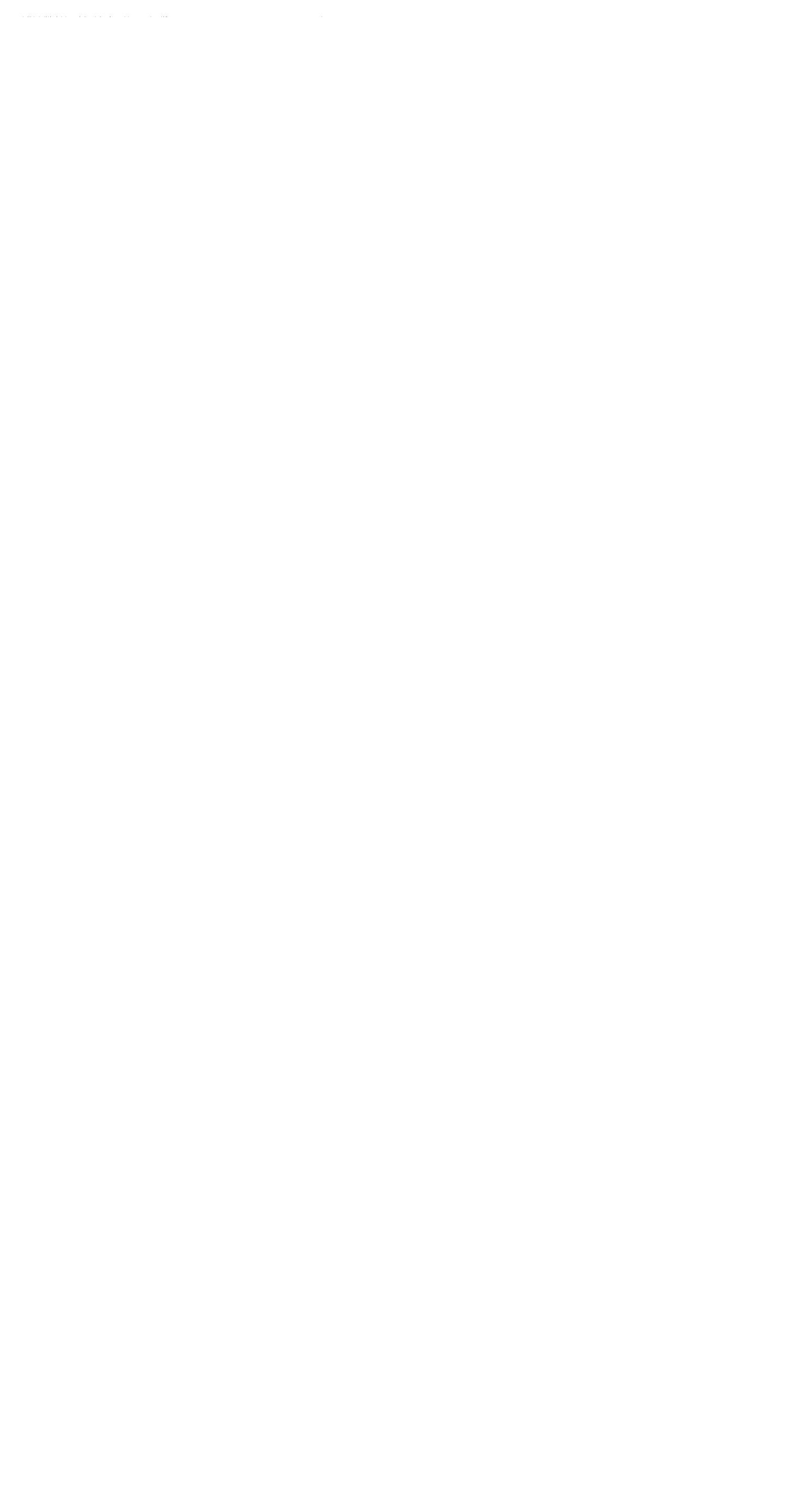

